\title{
Contribución a la meteorología colombiana
}

\author{
Jorge Alvarez Lleras
}

Rev. Acad. Colomb. Cienc. Ex. Fis. Nat. 1938, 2 (6): 207-226.

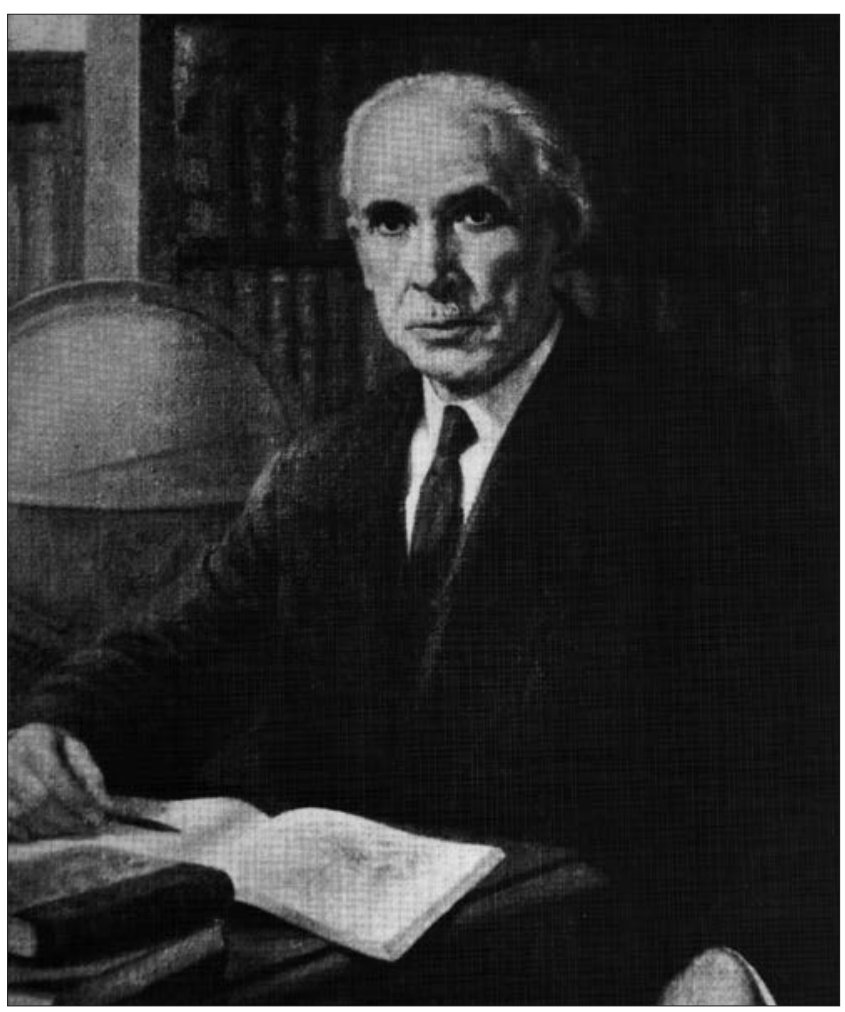

Jorge Alvarez Lleras (1885-1952)

Nació en 1885 en Bogotá. Se formó en el Colegio Nacional de San Bartolomé donde se graduó de bachiller en 1901; estudió en la Universidad Nacional de Colombia y obtuvo el título de Ingeniero Civil en 1906. Se destacó como ingeniero en el diseño y construcción de obras trascendentales para el país; fue docente de la Universidad de Nariño y de la Universidad Nacional de Colombia; desempeñó con altura diversos cargos en la administración pública. Fue director del Observatorio Astronómico Nacional y del Observatorio Meteorológico Nacional, así como fundador y primer presidente de la Academia Colombiana de Ciencias Exactas, Físicas y Naturales (oficializada en 1933). Además, creó la revista de la Academia, miembro muy activo de la Sociedad Geográfica de Colombia de la cual fue su también su presidente en 1925. Se destacó además por su trascendental contribución al desarrollo de la meteorología en Colombia, la cual inició en el año 1914 al vincularse como Ingeniero Auxiliar de Julio Garavito Armero, director entonces del Observatorio Astronómico Nacional y con quien elaboró
Este artículo es una versión de la publicación que el ingeniero Álvarez Lleras como "Encargado del Servicio Meteorológico del Observatorio Nacional, Colombia” había presentado en el Segundo Congreso Científico Panamericano, realizado en Washington en 1916, la cual quedo publicada en 1917 en los "Proceedings of the Second Scientific Pan American Congress". Tanto esta publicación como la versión que aquí se reproduce, publicada en 1938 en el volumen 2 de la revista de la Academia, son de gran valor porque detallan el desarrollo histórico de la meteorología en el país desde comienzos del siglo XIX hasta comienzos del XX, resumen, además, el avance del conocimiento del clima nacional y señalan las preocupaciones y los temas de discusión de comienzos del siglo XX en nuestro medio. Igualmente, ella muestra evidencia de la existencia de observaciones y mediciones meteorológicas en distintos lugares del país desde finales del siglo XIX. Tales publicaciones representan, además, un hito en el desarrollo histórico del país por su papel en el establecimiento del Servicio Meteorológico Nacional en 1916.

José Daniel Pabón, Ph.D.

Miembro correspondiente

una propuesta para establecer el servicio meteorológico, la cual expuso en la sesión de "Astronomía, Meteorología y Sismología" del Segundo Congreso Científico Panamericano reunido en Washington (diciembre 1915 - enero 1916); dicha propuesta impulsó el Decreto 74 de 1916 que creó el Servicio Meteorológico Nacional, del cual fue su director en 1918. Un año después viajó a Europa y a Estados Unidos con la misión de conocer los desarrollos en los servicios meteorológicos y de adquirir instrumentos. A su regreso, el Observatorio Astronómico Nacional y el Servicio Meteorológico Nacional estaban a cargo del sacerdote Simón Sarasola. Ocupó diversos cargos públicos relacionados con las obras civiles. En 1928 viajó de nuevo a Estados Unidos y retornó en 1930, año en el que se le nombró director del Observatorio Astronómico Nacional, cargo que ocupó hasta 1949.

Información biográfica suplementaria: http://www.accefyn. org.co/sp/academicos/Silla_2_Jorge_Alvarez_Lleras.htm 


\title{
CONTRIBUCION A LA METEOROLOGIA COLOMBIANA
}

\author{
ESTUDIO TOMADO DE LOS ANALES DEL SEGUNDO CONGRESO CIENTIFICO \\ PANAMERICANO DE WASHINGTON.
}

El presente estudio tiene por objeto resumir lo hecho hasta ahora por el Observatorio Nacional de Bogotá en el campo de la Meteorología.

Este Observatorio es astronómico y meteorológico, por consiguiente, en él se han efectuado observaciones meteorológicas tendientes a obtener un conocimiento completo del clima del país. Hasta ahora se ha logrado determinar exactamente el clima de Bogotá, según las variaciones periódicas que presentan una ley definida, anotando las anomalías que se presentan; mas, en lo que respecta a otras regiones, sólo se ha podido formar, agrupando datos diversos, una descripción somera, referente a altitudes, temperaturas y lluvia media.

Creemos que ya se ha llegado al conocimiento completo del clima de Bogotá, por cuanto las observaciones del barómetro no podrán suministrar iingún otro dato útil a la investigación de las causas de las variaciones de presión en la oscilación diurna o dinámica, y en la nocturna o elástica, ni en la previsión del cambio de tiempo. Las observaciones conducentes a la determinación de la humedad relativa, por medio del sicómetro o del evaporómetro, han suministrado ya cuanto podían dar de sí; la temperatura media está conocida, lo mismo que los límites entre los cuales oscilan la máxima y la mínima, el régimen general de los vientos reinantes da a conocer los movimientos de la zona de calmas, las peculiaridades referentes al descenso de la temperatura en julio $\mathrm{y}$ agosto, la existencia de lloviznas en estos meses y el retardo de la segunda época de lluvias, de suerte que, en términos generaies, últimamente sólo se ha buscado una confirmación de las conclusiones halladas por el sen̆or Director del Observatorio, en la primera serie de observaciones.

Ahora, nos proponemos determinar las características generales del clima, en todo el país, mediante la revisión de los datos tomados por los observadores que ya han trabajado en algunas poblaciones, y la centralización de los que se recojan en las estaciones meteorológicas que se funden con tal objeto.

Además de esto, el Observatorio se ocupará en la determinación de la radiación solar, por medio de un piriheliómetro Armstrong, de corriente; en la determinación de las variaciones diurnas y anua. les de la aguja magnética; en hallar el valor de la gravedad (hasta ahora, para las correcciones del barómetro, se ha hecho uso del valor calculado) y en el establecimiento de un servicio sismológico.

Así, pues, es necesario en este estudio dar una ligera idea de los trabajos que se han hecho hasta ahora, e indicar lo que falta por hacer, para obtener un conocimiento completo del clima del país.

En consecuencia, lo dividiremos en tres partes. En la primera se da una reseña histórica de los trabajos ejecutados en territorio colombiano, por observadores extranjeros o nacionales, poniendo de manifiesto la necesidad de continuar su obra. Esta reseña histórica no se había escrito hasta ahora, que sepamos; será, pues, de utilidad para valorar lo que se ha hecho en Colombia en la investigación de los fenómenos meteorológicos, para resolver los problemas con ellos relacionados, y que son los que de más cerca atañen al bienestar de los habitantes de un país. En la segunda parte se trata de dar una idea general de la distribución de las lluvias en todo el territorio, acopiando datos relativos a las diferentes regiones.

Esta idea será conveniente, por cuanto interesa despertar la atención al desarrollo de la Meteorología, e inclinar la acción oficial a la extensión de los centros de observación por toda la República. En los climas intertropicales no interesan las cuestiones relacionadas con el génesis y marcha de los ciclones, característicos de las zonas templadas, ni la previsión del tiempo para evitar siniestros marítimos o terrestres. En la mayor parte de las porciones habitadas del país no son de temer los huracanes destructores ni las fuertes granizadas, mas en cambio, el mayor número de sementeras es víctima de las irregularidades que se presentan en las estaciones lluviosas o secas. La determinación de la cantidad de lluvia caída y su distribución es, pues, el principal objeto de la Meteorología, en los países vecinos a la línea equinoccial, para proveer al establecimiento de oficinas de irrigación, estimular los cultivos de secano $y$ fomentar el desarro1 lo del aseguro agrícola.

En la tercera parte, se trata muy ligeramente de la fijeza del barómetro en la zona ecuatorial, para insistir en la importancia que tienen, en la región, los instrumentos que miden la presión atmosférica y que prestan grandes servicios a la altimetría. En esa parte, se dan las curvas de las oscilaciones ba- 


\section{Pon comatrou oc \\ DOW JOSE GELESTTKNO MỨTIS}

SE CONSTEUYÓ ESTE OBSERVATORIO DURANTE EL GOBIERNO

DEL VIREY DON REDEO MENDIHUETA.-EL ARQUITEGTO FRAY

DOMTNGO PETRES DIRIGI6 LA OBRA QUE TERMINÓ EL 20 DE AGOSTO DE I8OZ_CAXDAAS TRABAJÓ EN ÉL DESDE IOOS HASTA 1810.-EL GENERAL TOMAS C. DE MOSQUERA LE DIÓ IMPULSO

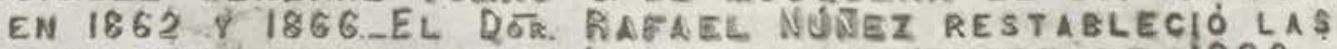
OBSERYACIONES ASTRONÓMICAS EN SETIEMBRE DE 1880 $Y$ LO DOTO DE INSTRUMENTOS Y REQLAMENTO SUS TRABAJOS EN IESI, CON LA COLABORACION PEL DOER. RIGARDO BEOERRA. SECRETARIO DE INSTRUCCLIOL PÚBLICA

JOSE MH: GONZÁLEZ BENITO, OIRECTOR DEL UESERVATORIO. TRIBUTA ESTE NOMENAUE DE RECONOCIMIENTO EL 20 DE JULLO DE 1881 .

Placa de mármol colocada en el paramento occidental del salón central. (Observatorio Astronómico)

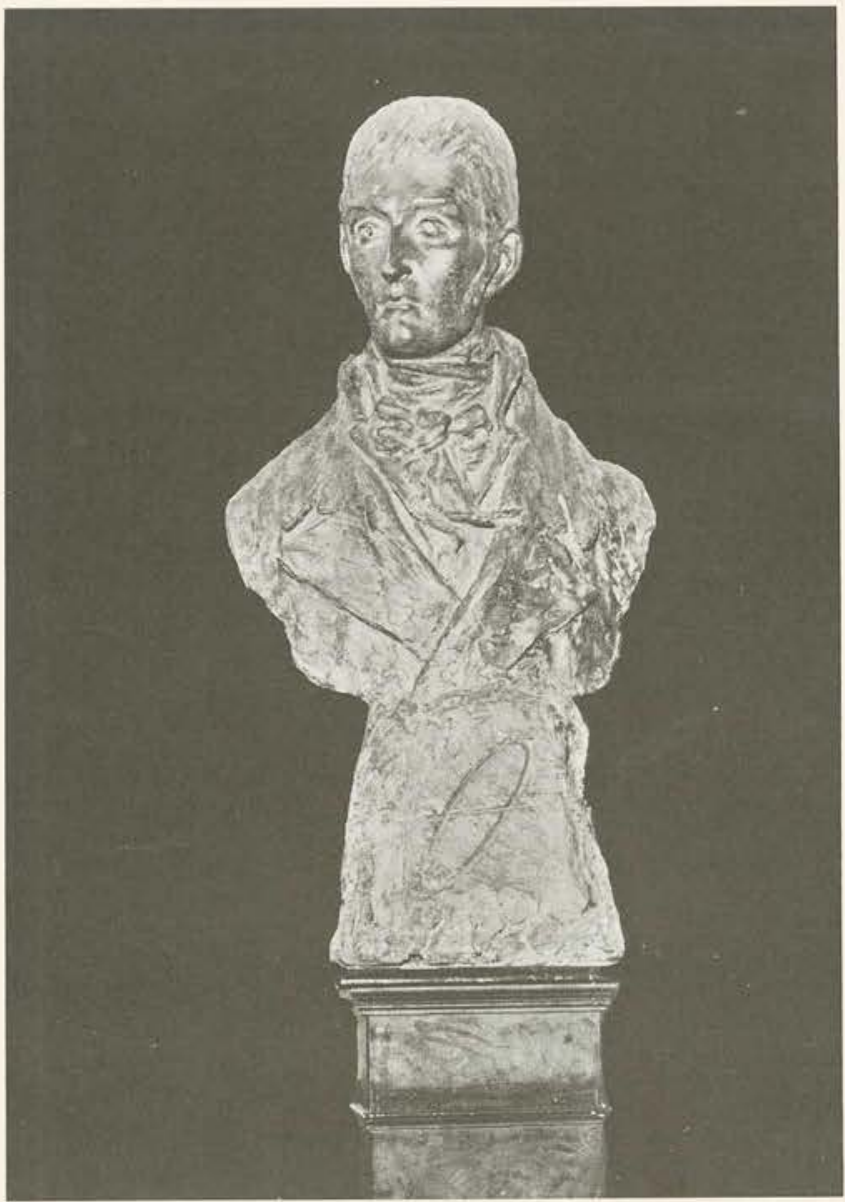

Busto de Caldas colocado en el salón central.

Obra del escultor colombiano Rosas. - Nótese el detalle con que el artista simbolizó la leyenda de "Oh! larga y negra partida!"

(Observatorio Astronómico) 
rométricas diurnas y anuales, con indicación de los métodos seguidos para determinarlas.

Además, para que se vea el servicio que el Observatorio presta a los ingenieros que se ocupan en medir las alturas de los innumerables pliegues del re. lieve orográfico del país, se describe un aparato construído personalmente por nosotros, y que sirve para reconocer los barómetros aneroides, corregirlos y patronarlos. Hasta la fecha del establecimiento de este servicios, los aparatos aneroides, grandemente usados por todos los ingenieros, daban lugar a frecuentes errores, por cuanto el transporte y el tiempo desarreglan poco a poco tales mecanismos, que entonces requieren ser enviados a la fábrica o patronados de nuevo. No es, pues, pequena la utilidad del aparato, que permite comparar el instrumento antes y después de su empleo, y por consiguiente obtener una media de las lecturas hechas, que se aproxime, lo más posible, a la verdad.

Si el corto espacio de que disponemos, nos hubiera permitido extendernos en una cuarta parte, la habríamos dedicado a las observaciones actinométricas y al estudio de la nebulosidad por medio del heliógrafo.

\section{HISTORIA}

Fueron debidos a los esfuerzos del sabio naturalista don José Celestino Mutis, los primeros pasos dados en el Virreinato de Nueva Granada en el sentido de iniciar observaciones ordenadas de los fenómenos meteorológicos y estudiar el clima ecuatorial americano, a tiempo que en Europa Borda, Lavoisier y Laplace pensaban que era posible la pre- visión del tiempo mediante la observación de los fenómenos atmosféricos.

Preciosos debieron ser los datos recogidos por orden y disposición de Mutis, cuando se fundó el Observatorio de Santa Fe (Bogotá) y se coleccionaron los trabajos de la "Expedición Botánica". Desgraciadamente, si es cierto que parte importante de los trabajos de esta Expedición, en lo que se refiere a Zoología y estudio de la Flora, fueron aprovechados más tarde por los naturalistas Lagasca y Pabón, españoles, y por el ilustrado botánico granadino, señor José Triana (Triana y Planchón, "Flora Colombiana"), también lo es que, en cuanto a apuntaciones sobre fenómenos meteorolo. gicos, la obra de la célebre "Expedición" puede darse por perdida, ya que en Madrid es punto menos que imposible revisar los Archivos coloniales, que carecen de indices convenientes.

Según esto, las primeras observaciones anotadas que poseemos, se deben al prócer don Francisco José de Caldas, quien trabajó para establecerlas regularmente, no sólo en Santa Fe, sino en otros lugares del Virreinato. En 1807 hizo Caldas, en Bogotá, observaciones meteorológicas durante todo el año, según lo refiere Boussingault ("Annales de Chimie et Physique", 1826) ; mas de ellas no se pudieron encontrar sino extractos incompletos. En 1808 Caldas publicó en el "Semanario de la Nueva Granada", las observaciones hechas por él personalmente en el Observatorio de Santa Fe, observaciones que se extienden a los seis primeros meses de ese año, y que extractamos en el primer cuadro que acompaña a esta reseña histórica.

Cuadro de las observaciones meteorológicas hechas en el año de 1808 por Don Francisco José de Caldas en el Observatorio Astronómico Nacional

\begin{tabular}{|c|c|c|c|c|c|}
\hline & \multirow{2}{*}{ MESES } & \multicolumn{2}{|c|}{ Barómetro } & \multirow{2}{*}{$\begin{array}{c}\text { Temperatura } \\
\text { media }\end{array}$} & \multirow{2}{*}{$\begin{array}{l}\text { Pluvió } \\
\text { metro }\end{array}$} \\
\hline & & Máxima & Mínima & & \\
\hline & & \multicolumn{2}{|c|}{ Metros } & Centígrados & Mm. \\
\hline Enero & $\ldots \ldots \ldots \ldots \ldots \ldots$ & 0.5617 & 0.5594 & $14^{\circ} 16$ & 93.5 \\
\hline Febrero & $0 \quad \ldots \ldots \ldots \ldots \ldots \ldots \ldots \ldots \ldots \ldots \ldots \ldots \ldots \ldots$ & 0.5615 & 0.5594 & $14^{\circ} 14$ & 42.3 \\
\hline Marzo & $\ldots \ldots \ldots \ldots \ldots \ldots \ldots \ldots \ldots \ldots \ldots \ldots$ & 0.5618 & 0.5595 & $14^{\circ} 21$ & 177.5 \\
\hline Abril . & 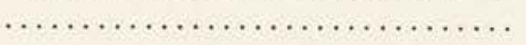 & 0.5618 & 0.5595 & $14^{\circ} 33$ & 201.6 \\
\hline Mayo . & 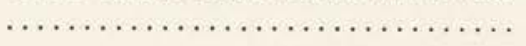 & 0.5621 & 0.5599 & $14^{\circ} 30$ & 139.0 \\
\hline Junio . & $\ldots \ldots \ldots \ldots \ldots \ldots \ldots \ldots \ldots \ldots \ldots$ & 0.5621 & 0.5598 & $14^{\circ} 31$ & 42.3 \\
\hline
\end{tabular}

NOTA.-Los datos de este cuadro vieron la luz pública en el "Semanario de Nueva Granada" y fueron reproducidos en los "Anales de Instruceión Páblica" en 1886. La columna titulada temperatura media debe referirse a la temperatura media durante el día, o sea, al intervalo comprendido entre las 6 a. $\mathrm{m}$. $\mathrm{y}$ las $6 \mathrm{p}$. $\mathrm{m}$. Se ignora qué clase de correcciones hizo Caldas a sus observaclones, lo mismo que la calidad y procedencia de los instrumentos que usó.

Probablemente, comprometido ya en el movimien. to de ideas políticas, iniciado por don Antonio Nariño, Caldas interrumpió sus observaciones hasta el año de 1810, año en que se publicaron las hechas en el mes de enero. Entonces estalló la revolución del 20 de julio, $\mathbf{y}$ arrastrado por los sucesos, hubo de interrumpir sus trabajos para siempre.

Durante la lucha por la independencia de la Corona y en los primeros tiempos, después del advenimiento de la República, los estudios del clima y de los fenómenos meteorológicos se abandonaron completamente, tanto en Santa Fe de Bogotá, como en otros lugares, donde Caldas había logrado despertar afición a los estudios físicos, y donde se habian emprendido labores de investigación merced a la influencia ilustrada del Gobierno español.

Este abandono perduró hasta el año de 1823 , cuando a instancias del Gobierno de la Gran Colombia, y por influjo del Barón de Humboldt, vinieron hombres de ciencia a establecer en Bogotá estudios de Física, Matemáticas y Ciencias Naturales. Entonces Rivero, Boussingault y Roulin efec- 
tuaron observaciones meteorológicas, que se publicaron en Europa por Ferrussac, y que después reprodujo el General Joaquín Acosta (Viajes Científicos a los Andes Ecuatoriales - 1849), y completó Rivero en sus "Memorias Científicas" publi- cadas en Bruselas en 1857. De las observaciones de Boussingault, que se refieren al lapso transcurrido de mediados de 1823 a mediados de 1824 , copiamos un cuadro, a continuación de las observaciones de Caldas.

Cuadro de las observaciones meteorológicas hechas en los años de 1823 y 1824, por Mr. Boussingault, en la ciudad de Bogotá

\begin{tabular}{|c|c|c|c|c|c|}
\hline \multirow{2}{*}{ Año de 1823-Meses } & \multicolumn{2}{|c|}{ Barómetro } & \multirow{2}{*}{ Año de 1824-Meses } & \multicolumn{2}{|c|}{ Barómetro } \\
\hline & Máxima & Mínima & & Máxima & Mínima \\
\hline & Metros & Metros & & Metros & Metros \\
\hline & & & Enero & 0.5616 & 0.5593 \\
\hline 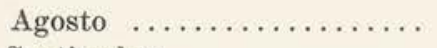 & 0.5622 & 0.5600 & Febrero $\ldots \ldots \ldots \ldots \ldots$ & 0.5617 & 0.5594 \\
\hline Septiembre...$\ldots \ldots \ldots \ldots$ & 0.5623 & 0.5597 & Marzo $\ldots \ldots \ldots \ldots \ldots$ & 0.5619 & 0.5597 \\
\hline Octubre $\ldots \ldots \ldots \ldots \ldots \ldots$ & 0.5620 & 0.5694 & Abril $\ldots \ldots \ldots$ & 0.5624 & 0.5599 \\
\hline Noviembre $\ldots \ldots \ldots \ldots \ldots$ & 0.5616 & 0.5594 & Mayo $\ldots \ldots \ldots \ldots \ldots$ & 0.5619 & 0.5595 \\
\hline Diciembre...$\ldots \ldots \ldots \ldots$ & 0.5633 & 0.5589 & Junio ............... & 0.5622 & 0.5602 \\
\hline & & & Julio .............. & 0.5622 & 0.5597 \\
\hline
\end{tabular}

Temperatura del aire, $15^{\circ} 3$. pluviometro.

NOTA.-Se ignora la clase de instrumentos usados, lo mismo que la temperatura media absoluta. No hay datos del

Cuadro de las observaciones hechas en Bogotá, por el Sr. Gral. Joaquín Acosta, en los años de 1833, 1834 y 1835, con un barómetro de Bunten, de sifón, comparado con el del Observatorio de París, y un termómetro centígrado, del mismo fabricante

\begin{tabular}{|c|c|c|c|c|}
\hline MESES & $\begin{array}{l}9 \text { a. m. } \\
\text { Barómetro }\end{array}$ & $\begin{array}{l}\text { Tempe- } \\
\text { ratura }\end{array}$ & $\begin{array}{c}3 \text { p. m. } \\
\text { Barómetro }\end{array}$ & $\begin{array}{l}\text { Tempe- } \\
\text { ratura }\end{array}$ \\
\hline Año de 1833 & Metros & & Metros & \\
\hline 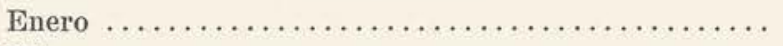 & 0.5620 & $13^{\circ} 30$ & 0.5604 & $17^{\circ} 70$ \\
\hline 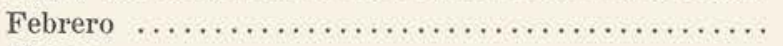 & 0.5623 & $13^{\circ} 50$ & 0.5604 & $17^{\circ} 50$ \\
\hline 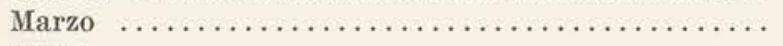 & 0.5618 & $16^{\circ} 50$ & 0.5604 & $19^{\circ} 70$ \\
\hline 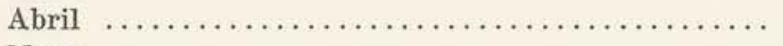 & 0.5618 & $15^{\circ} 90$ & 0.5606 & $18^{\circ} 00$ \\
\hline 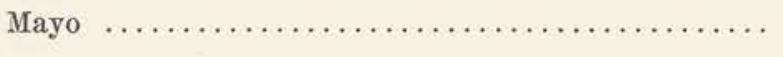 & 0.5623 & $15^{\circ} 70$ & 0.5607 & $17^{\circ} 40$ \\
\hline 1834 & & & & \\
\hline 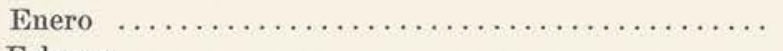 & 0.5625 & $12^{\circ} 80$ & 0.5607 & $18^{\circ} 10$ \\
\hline 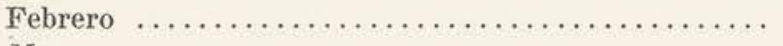 & $\ldots \ldots$ & $\ldots$. & $\ldots \ldots$ & $\cdots \cdots$ \\
\hline 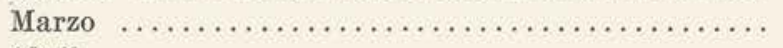 & $\ldots \ldots$ & $\cdots \cdot$ & ...... & $\cdots \cdots$ \\
\hline 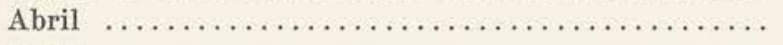 & $\ldots \ldots$ & $\ldots \ldots$ & $\ldots \ldots$ & .... \\
\hline 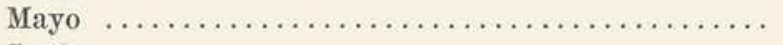 & 0.5628 & $16^{\circ} 40$ & 0.5609 & $17^{\circ} 9$ \\
\hline 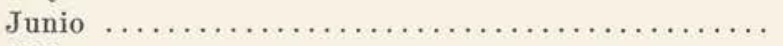 & 0.5623 & $17^{\circ} 70$ & 0.5608 & $17^{\circ} 0$ \\
\hline Julio $\ldots \ldots \ldots \ldots \ldots \ldots \ldots \ldots \ldots \ldots \ldots \ldots \ldots \ldots \ldots \ldots \ldots \ldots$ & 0.5628 & $17^{\circ} 17$ & 0.5607 & $21^{\circ} 0$ \\
\hline 1835 & & & & \\
\hline 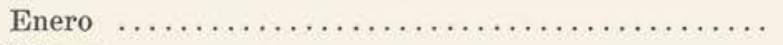 & 0.5619 & $14^{\circ} 70$ & 0.5597 & $17^{\circ} 30$ \\
\hline 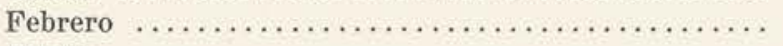 & $\ldots \ldots$ & $\ldots \ldots$ & $\ldots \ldots$ & $\ldots \ldots$ \\
\hline 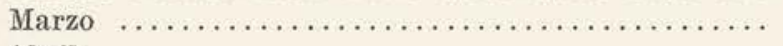 & 0.5619 & $15^{\circ} 60$ & 0.5600 & $16^{\circ} 10$ \\
\hline 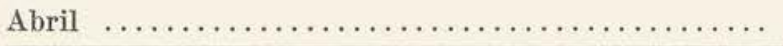 & 0.5624 & $16^{\circ} 70$ & 0.5602 & $16^{\circ} 30$ \\
\hline
\end{tabular}

NOTA.-Estos datos se volvieron a publicar en los "Anales de Instrucción Pública", en el año de 1887. Las indicaciones consignadas en el cuadro están únicamente corregidas de temperatura. Deben corregirse de capilaridad y gravedad. No hay datos del pluviómetro.

En el año de 1828 publicó el doctor Benito Osorio unas observaciones verificadas en 1827 , y desde el año de 1831, el General Acosta, deseoso de continuar la obra de Boussingault (véase la correspondencia de Humboldt), hizo observaciones en lugares distintos, con cuidado y prolijidad. Las que verificó en el Observatorio de Bogotá se debieron a la iniciativa del Gobierno del General Santander, quien nombró a Acosta "Director del Museo y del Observatorio Nacional".

De los datos tomados por Acosta, sólo hemos visto los que se refieren a $l o s$ años de 1833,1834 y 1835 , y que, en un cuadro incompleto, copiamos a continuación de las observaciones de Boussingault. Por aquella época las ideas de Humboldt respecto a las variaciones de la altura del barómetro y a las in- 
fluencias de la latitud y la altitud en el trazado de las líneas isotérmicas, habían dado cierta resonancia en el mundo científico a los trabajos de los físi. cos conocedores de las regiones equinocciales. La circunstancia de que tanto Colombia, como el Ecuador, dilatan su territorio en la proximidad del ecuador, $\mathrm{y}$ poseen regiones situadas a alturas muy diversas sobre el nivel del mar, permitió fijar la atención en la influencia marcada de la altitud sobre la presión y en la fijeza relativa del barómetro en las regiones equinocciales. De esta suerte, no sólo tuvieron importancia especial los trabajos de Humboldt y Boussingault, sino que relacionados íntimamente con los de Caldas, Acosta y otros, granadinos y ecuatorianos, sirvieron de base para el estudio de la Climatología colombiana y de la zona tórrida americana. (A. Humboldt - "Viaje a los países equinocciales del Nuevo Continente"). Es de esta manera como se explica la cooperación de Bourdon, Gaudot, Roulin y Boussingault, que cediendo a los deseos de Humboldt, trabajaron en asocio de ingenieros americanos, en la determinación de las principales características de nuestros climas.

Después de Acosta, sólo hasta la Presidencia primera del ilustrado y progresista General Mosquera, los estudios meteorológicos merecieron atención de parte del Gobierno. En 1835 vieron la luz pública, en la "Crónica Semanal", varias observaciones esporádicas referentes al clima de Bogotá, mas sólo hasta el año de 1848 publicó el General Mosquera, en la "Gaceta Oficial" sus propias observaciones. En este año el Gobierno de Nueva Granada contrató el levantamiento de la Carta con el Coronel Codazzi, anex́́ el Observatorio al Colegio Militar, regentado por el Profesor Aimé Bergeron, dotó al Observatorio con algunos instrumentos, favoreció las expediciones cientificas por distintas regiones, y no omitió esfuerzo en el sentido de obtener datos referentes a Climatología, Geografía Física y Geología del territorio nacional.

Durante algún tiempo, después de la dirección del General Acosta, fueron Directores del Observatorio Astronómico y Meteorológico, don Benedicto Domínguez y don Francisco Javier Matiz, sin dejar dato alguno relativo a observaciones practicadas entonces.

De los datos esporádicos, publicados por don José Caicedo Rojas en "El Pasatiempo" (año de 1852) y por P. Cornette, en el "Anuario Meteorol6. gico de Francia" (sobre observaciones efectuadas en Bogotá, en 1856), no hemos podido tomar nota por carecer de los informes bibliográficos correspondientes.

Después del cuadro en que figuran los datos acopiados por el General Acosta, insertamos un compendio de las observaciones hechas en Bogotá, desde el 27 de mayo hasta el 30 de junio de 1857 , por el ilustrado naturalista don Ezequiel Uricoechea, con el objeto de anotar el hecho de que las correcciones barométricas deben dar resultados dudosos en las medias de las presiones observadas en Bogotá hasta 1893.

NOTA DEL DR. URICOECHEA.- "Nos servimos del baróme. tro No 105 de Frastre, de nivel constante. Tanto éste como nues tro termómetro han sido comparados con los del Observatorio Imperial de Francia, por nuestro malogrado amigo M. Goujon. Publicamos la presion atmosférica sin reducción a $0^{\circ}$. Anotamos dos obras excelentes, que tienen este objeto: "Meteorological Tables", por Guyoto, Washington, 1851, y las tablas de Oltmans, 1839, que son generalmente usadas, El punto de agua hirviendo ha sido determinado en Bogotá por medio de un hipsometro de Regnault. Todas las observaciones han sido hechas de la misma manera que se hacen en el Real Observatorio de Bruselas, donde durante ocho meses tuvimos la honra de estudiar y practicar al lado de su ilustre Director, M. Quetelet. Habiéndosenos roto en el transporte de Europa a Bogotá los termómetros de máxima y mínima y careciendo absolutamente de anemómetro, galvanómetro $y$ aparatos para la inclinación y decli. nacion de la aguja magnética, no nos ha sido posible observar nación de la aguja magnética, no nos ha sido posible observar
otros fenómenos meteorologicos. Las divisiones de los termometros son centesimales. El barómetro da los milésimos y sus fracciones. El agua hierve en Bogotá a los 90.32 e. Más tarde nos proponemos discutir la altura absoluta en Bogotá por los resultados obtenidos con el barómetro y el punto del agua hirviendo".

Cuadro de las observaciones meteorológicas hechas en Bogotá, desde el 27 de mayo hasta el 30 de junio de 185\%, por Ezequiel Uricoechea

\begin{tabular}{|c|c|c|c|c|c|c|c|c|c|c|}
\hline \multirow{2}{*}{\multicolumn{2}{|c|}{ DIAS }} & \multicolumn{3}{|c|}{ Termómetro exterior } & \multicolumn{3}{|c|}{$\begin{array}{c}\text { Termómetro del } \\
\text { Barómetro }\end{array}$} & \multicolumn{3}{|c|}{ Barómetro } \\
\hline & & Grados & & & & & Grados & & & \\
\hline 27 & $\ldots \ldots \ldots \ldots \ldots$ & 16.2 & 12.0 & 12.7 & 14.8 & 14.6 & 14.6 & 0.56585 & 0.56440 & 0.56500 \\
\hline 28 & $\ldots \ldots \ldots \ldots$ & 15.1 & 13.5 & 13.5 & 14.2 & 14.5 & 14.7 & 0.56530 & 0.56440 & 0.56380 \\
\hline 29 & $\ldots \ldots \ldots \ldots$ & 17.0 & 13.1 & 12.6 & 14.8 & 14.5 & 14.6 & 0.56460 & 0.56280 & 0.56420 \\
\hline 30 & $\ldots \ldots \ldots \ldots$ & 17.0 & 13.2 & 12.5 & 14.7 & 14.4 & 14.7 & 0.56480 & 0.56435 & 0.56490 \\
\hline 31 & $\ldots \ldots \ldots \ldots$ & 17.1 & 13.3 & 12.6 & 14.0 & 14.5 & 14.6 & 0.56590 & 0.56440 & 0.56550 \\
\hline 1 & $\ldots \ldots \ldots \ldots$ & 19.5 & 15.0 & 12.2 & 14.5 & 14.8 & 14.7 & 0.56470 & 0.56300 & 0.56400 \\
\hline 2 & $\ldots \ldots \ldots \ldots \ldots$ & 17.3 & 14.1 & 12.8 & 14.7 & 15.0 & 14.7 & 0.56470 & 0.56309 & 0.56400 \\
\hline 3 & n......... & 16.7 & 17.1 & 11.2 & 14.4 & 14.9 & 13.9 & 0.56440 & 0.56250 & 0.56430 \\
\hline 4 & $\ldots \ldots \ldots \ldots \ldots$ & 16.5 & 17.0 & 9.9 & 13.6 & 13.5 & 13.5 & 0.56485 & 0.56300 & 0.56450 \\
\hline 5 & $\ldots \ldots \ldots \ldots \ldots$ & 16.3 & 16.3 & 10.9 & 13.6 & 14.7 & 13.9 & 0.56480 & 0.56330 & 0.56410 \\
\hline 6 & $\ldots \ldots \ldots \ldots \ldots$ & 15.6 & 16.4 & 12.9 & 13.7 & 15.0 & 14.2 & 0.56450 & 0.56270 & 0.56430 \\
\hline 7 & $\ldots \ldots \ldots \ldots \ldots$ & 17.8 & 17.4 & 12.6 & 14.9 & 15.5 & 14.4 & 0.56380 & 0.56190 & 0.56345 \\
\hline 8 & $\ldots \ldots \ldots \ldots \ldots$ & 17.5 & 15.5 & 12.0 & 14.9 & 15.5 & 15.0 & 0.56435 & 0.56265 & 0.56410 \\
\hline 9 & n.......... & 16.5 & 16.7 & 13.7 & 14.6 & 15.1 & 14.9 & 0.56397 & 0.56280 & 0.56370 \\
\hline 10 & $\ldots \ldots \ldots \ldots \ldots$ & 17.0 & 17.8 & 12.1 & 14.7 & 15.4 & 14.8 & 0.56330 & 0.56145 & 0.56280 \\
\hline
\end{tabular}




\begin{tabular}{|c|c|c|c|c|c|c|c|c|c|c|}
\hline \multirow{2}{*}{\multicolumn{2}{|c|}{ DIAS }} & \multicolumn{3}{|c|}{ Termómetro exterior } & \multicolumn{3}{|c|}{$\begin{array}{l}\text { Termómetro del } \\
\text { barómetro }\end{array}$} & \multicolumn{3}{|c|}{ Barómetro } \\
\hline & & Grados & & & & & Grados & & & \\
\hline 11 & $\ldots \ldots \ldots \ldots$ & 16.4 & 17.5 & 11.38 & 14.4 & 15.3 & 14.5 & 0.56275 & 0.56150 & 0.56245 \\
\hline 12 & $\ldots \ldots \ldots \ldots$ & 18.3 & 17.1 & 12.9 & 14.7 & 15.4 & 14.9 & 0.56360 & 0.56300 & 0.56370 \\
\hline 13 & $\ldots \ldots \ldots \ldots$ & 18.1 & 18.2 & 13.8 & 15.2 & 15.8 & 14.9 & 0.56410 & 0.56240 & 0.56370 \\
\hline 14 & $\ldots \ldots \ldots \ldots$ & 16.7 & 17.4 & 13.9 & 14.8 & 15.5 & 15.1 & 0.56407 & 0.56210 & 0.56400 \\
\hline 15 & $\ldots \ldots \ldots \ldots$ & 17.1 & 18.1 & 11.9 & 15.0 & 15.8 & 15.2 & 0.56380 & 0.56260 & 0.56310 \\
\hline 16 & $\ldots \ldots \ldots \ldots$ & 17.2 & 20.0 & 14.0 & 14.8 & 15.6 & 15.1 & 0.56365 & 0.56265 & 0.56407 \\
\hline 17 & $\ldots \ldots \ldots \ldots$ & 16.4 & 18.9 & 11.9 & 15.5 & 15.9 & 15.1 & 0.56410 & 0.56285 & 0.56495 \\
\hline 18 & $\ldots \ldots \ldots \ldots$ & 16.5 & 19.5 & 14.4 & 14.9 & 16.6 & 15.3 & 0.56435 & 0.56340 & 0.56405 \\
\hline 19 & $\ldots \ldots \ldots \ldots$ & 16.8 & 15.9 & 11.8 & 15.3 & 15.5 & 14.7 & 0.56410 & 0.56265 & 0.56460 \\
\hline 20 & $\ldots \ldots \ldots \ldots$ & 12.8 & 15.9 & 12.4 & 14.3 & 15.0 & 14.6 & 0.56465 & 0.56265 & 0.56416 \\
\hline 21 & $\ldots \ldots \ldots \ldots$ & 16.0 & 16.1 & 11.1 & 14.4 & 14.0 & 14.5 & 0.56510 & 0.56350 & 0.56500 \\
\hline 22 & $\ldots \ldots \ldots \ldots$ & 18.0 & 17.5 & 11.0 & 14.0 & 15.4 & 14.4 & 0.56450 & 0.56305 & 0.56410 \\
\hline 23 & $\ldots \ldots \ldots \ldots$ & 18.8 & 17.3 & 13.3 & 14.9 & 15.2 & 14.7 & 0.56423 & 0.56300 & 0.56330 \\
\hline 24 & $\ldots \ldots \ldots \ldots$ & 19.1 & 18.9 & 13.2 & 15.0 & 15.2 & 14.7 & 0.56379 & 0.56205 & 0.56368 \\
\hline 25 & $\ldots \ldots \ldots \ldots$ & 17.5 & 15.9 & 12.95 & 14.9 & 15.2 & 14.5 & 0.56380 & 0.56227 & 0.56380 \\
\hline 26 & $\ldots \ldots \ldots \ldots$ & 16.0 & 16.8 & 11.8 & 14.8 & 15.4 & 14.5 & 0.56428 & 0.56256 & 0.56418 \\
\hline 27 & $\ldots \ldots \ldots \ldots$ & 16.2 & 17.5 & 13.3 & 14.5 & 15.7 & 14.6 & 0.56476 & 0.56353 & 0.56426 \\
\hline 28 & $\ldots \ldots \ldots \ldots$ & 14.0 & 17.3 & 13.9 & 13.7 & 15.5 & 14.8 & 0.56437 & 0.56307 & 0.56334 \\
\hline 29 & $\ldots \ldots \ldots \ldots$ & 17.5 & 15.8 & 12.5 & 15.2 & 15.5 & 14.8 & 0.56606 & 0.56457 & 0.56417 \\
\hline 30 & $\ldots \ldots \ldots \ldots$ & 16.4 & 18.0 & 12.6 & 14.7 & 15.3 & 14.1 & 0.56649 & 0.56296 & 0.56425 \\
\hline
\end{tabular}

En el mismo año de 1858 , M. Frisak practicó varias observaciones, conjuntamente con la determinación de la declinación de la aguja magnética; y en 1859 don José Cornelio Borda se encargó de la Dirección del Observatorio, sin que se sepa cuáles fueron sus trabajos en el campo de la Meteorología.

La guerra civil de 1860 paralizó no sólo la reorganización del Observatorio sino la continuación de los trabajos de la Comisión Corográfica, de la cual formaron parte, después de la muerte de Codazzi, los señores Manuel Ponce, Manuel María Paz e Indalecio Liévano, conocido matemático nacional, quien después de su regreso de la Costa Atlántica, determinó la altura del barómetro en Bogotá.

Esta determinación se hizo por medio de observaciones simultáneas: en Bogotá observó la columna barométrica, en el salón principal del Observatorio el señor Liévano, y en Cartagena, en un sitio colocado a una altura media sobre el nivel del mar, de $8.5^{\mathrm{m}}$, observó el señor William Chandless. En ambos lugares se tomó la temperatura del aire ambiente. El promedio de 18 observaciones simultáneas fue:

En Cartagena.-Agua hirviente, $99^{\circ} 96$, temperatura ambiente, $27^{\circ} 32$.

En Bogotá.-Agua hirviente, $91^{\circ} 73$, temperatura ambiente, $15^{\circ} 40$. Para la temperatura de ebullición en Bogotá dan las tablas de Regnault, para la altura de la columna barométrica, $561.01 \mathrm{~mm}$.

Fuéra de este trabajo, el señor Liévano dirigió algunas observaciones meteorológicas en 1862, observaciones que interrumpió por algún tiempo y continuó después en 1868, 1871 y 1872.

Realmente, donde se han verificado observaciones meteorológicas con alguna regularidad ha sido en Bogotá, ya que en otras poblaciones sólo se encuentran datos aislados, generalmente tomados por viajeros que han atravesado rápidamente el territorio. Caldas comprendió la necesidad de extender el radio de acción a otros puntos y por eso trabajó con ahinco. En sus viajes por diversas regiones del país practicó observaciones barométricas, hipsométricas, higrométricas y de temperatura, y las acompañó con descripciones de los climas, llenas de viveza descriptiva y apuntaciones críticas ilustradas. Para poner un ejemplo, óigase cómo describe la época de lluvias en las feraces regiones del Chocó:

"Llueve la mayor parte del año. Ejércitos inmensos de nubes se lanzan en la atmósfera del seno del Océano Pacífico. El viento $O$, que reina constantemente en estos mares, las arroja dentro del Continente, los Andes las detienen en la mitad de su carrera. Aquí se acumulan y dan a esas montañas un aspecto sombrio y amenazador: el cielo desaparece, por todas partes no se ven sino nubes pesadas y negras que amenazan a todo ser viviente. Una calma sofocante sobreviene; éste es el momento terrible; ráfagas de viento dislocadas arrancan árboles enormes; explosiones eléctricas, truenos espantosos; los ríos salen de su lecho, el mar se enfurece, olas inmensas vienen a estrellarse sobre las costas; el cielo se confunde con la tierra y todo parece que anuncia la ruina del universo. En medio de este conflicto el viajero palidece, mientras que el habitante del Chocó duerme tranquilo en el seno de su familia. Una larga experiencia le ha enseñado que los resultados de estas convulsiones de la naturaleza son pocas veces funestos y que todo se reduce a luz, agua y ruido, y que dentro de pocas horas se restablece el equilibrio, y la serenidad".

Verdadero inventor del hipsómetro, Caldas fue uno de los primeros que notaron la estabilidad de la columna barométrica en la zona ecuatorial y las variaciones de la temperatura de ebullición del 


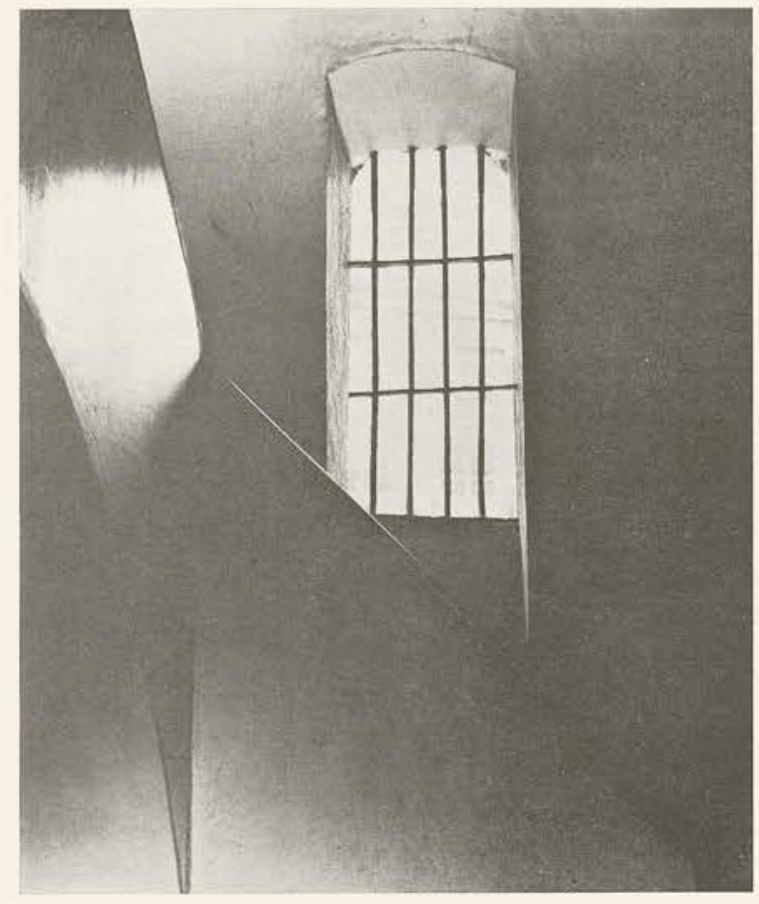

Detalle de la escalera construida sobre arcos de tres centros, por tramos de cinco escalones. (Observatorio Astronómico)

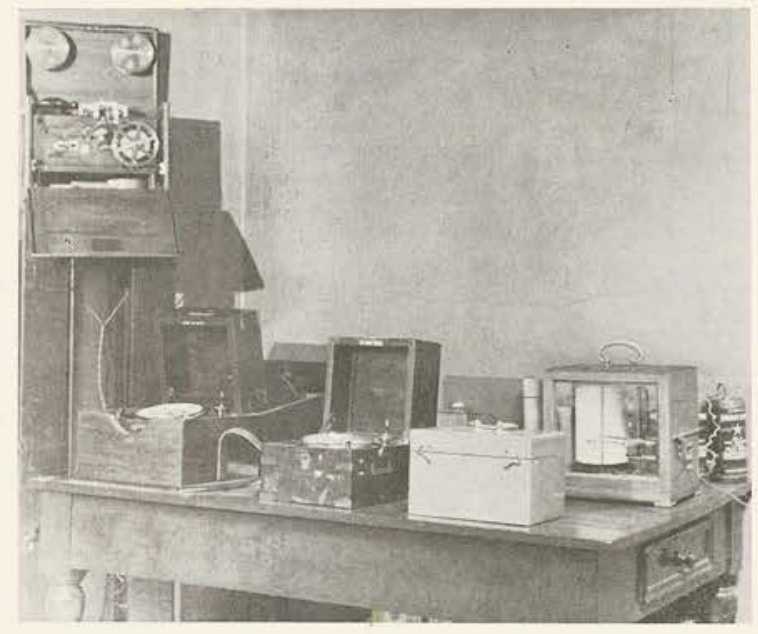

Detalles de los cronómetros de tiempos sidéreo y medio y de los cronógrafos registradores. (Casilla meridiana - Observatorio Astronómico)

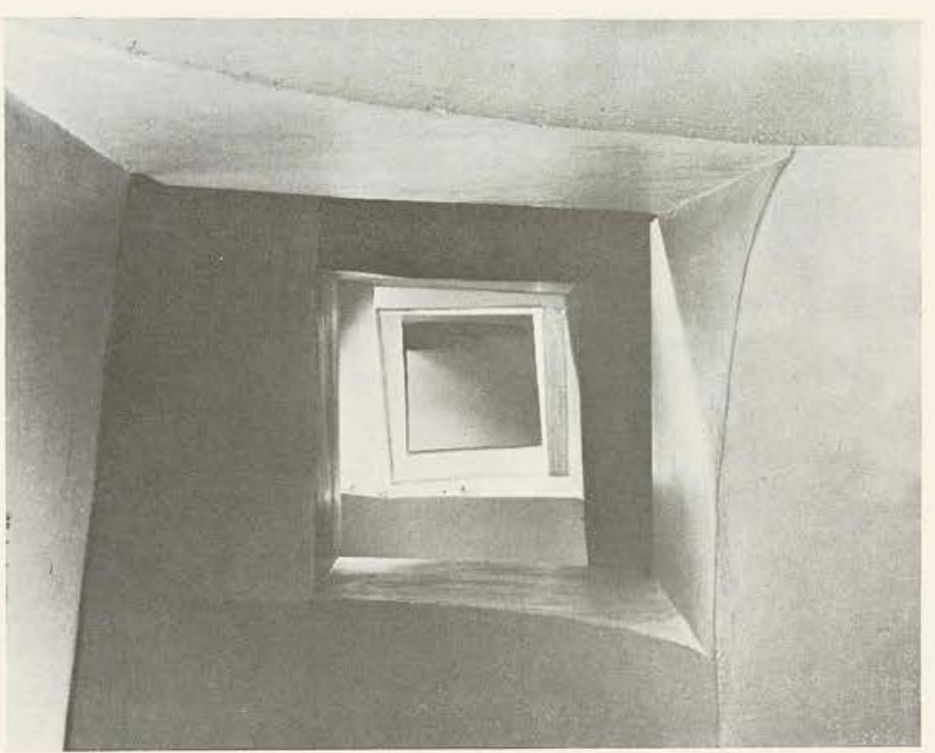

Aspecto de los arcos de la escalera dicha, en espiral, vistos por debajo. (Observatorio Astronómico)

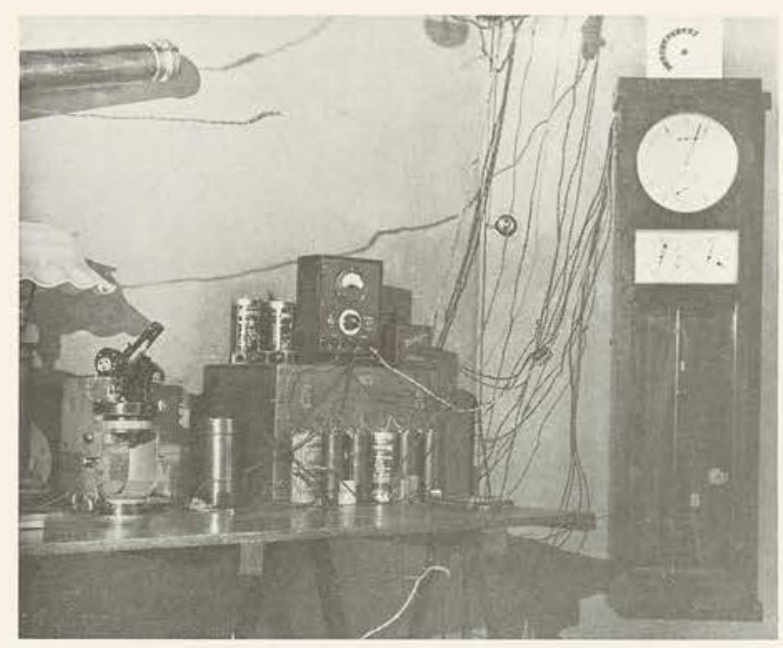

Péndulo (de la Syncronome Co. Ltd.) sincronizado con e "Shortt", que se encuentra en el jardin, y detalles de su instalación: corrector magnético, relevo para envio de señales etc. (Casilla meridiana-Observatorio Astronómico) 
agua a diversas alturas sobre el nivel del mar, por cuanto él se encontraba en condiciones favorables para hacer esta observación, ya que las variaciones accidentales de la presión atmosférica, en las zonas templadas, hacían imposible verificar esta experiencia sin ninguna idea preconcebida, a este respecto. $\mathrm{Ni}$ el mismo Humboldt, quien usaba en sus ascensiones un aparato termométrico que le recomendó Saussure y que le merecía poca confianza", pudo notar el fenómeno en Europa. En una conversación que Caldas tuvo con el viajero alemán, relativa a las experiencias de Herberden, conversación relatada por el mismo Caldas, se lee:

"En las primeras conversaciones le traté sobre la materia, y me dijo que Sucio había trabajado sobre el particular y había enseñado el método de medir las montañas sin el barómetro. Ya se deja ver con qué ansia oiría al Barón sobre este punto. Yo cré, vi mis ideas como una cosa que había nacido en mi espíritu a veinte años de agotada en Europa, y sólo traté de presentar unas ideas confirmatorias de la teoría de Sucio, apreciables por ser en grandes elevaciones y en la vecindad del Ecuador. Insté a este sabio viajero por el exponente y por las experiencias de Sucio, pero cuando quiso tomarlo de sus manuscritos, halló que Sucio no había pensado en el agua hirviendo y que este físico sólo era el perfeccionador del método de Heberden, que asigna 640 pies por un grado menos en el termómetro expuesto al aire, y vuelvo yo a entrar en posesión de mi pequeño descubrimiento".

En realidad, Humboldt ya había usado, en su ascensión al pico de Tenerife, el método empleado por Caldas, mas nada preciso había sentado sobre el particular. Habiendo Caldas efectuado varias expediciones, a todas las alturas sobre el nivel del mar, $y$ habiendo residido largo tiempo en vecindades de la línea equinoccial, estuvo en aptitud para formular las leyes, que él tuvo como suyas, antes que el mismo Humboldt.

Por supuesto que a Humboldt debemos las nociones principales que se refieren a la Meteorología de las regiones intertropicales. Por tanto, la nación colombiana es la primera en reconocer los méritos de ese ilustre sabio. Con Colombia y sus hombres mantuvo siempre Humboldt relaciones amistosas, como lo prueba la correspondencia del General Acosta; a él se debió la venida de Boussingault y que, años después, el Gobierno de la República encargara el levantamiento de la Carta al Coronel Codazzi.

También este ilustre viajero y geógrafo contribuý a la Meteorología del país, pues, en sus "Notas de viaje", consignó interesantes observaciones suyas, sobre el clima de las regiones que visitaba. Así, por ejemplo, para explicar el retardo de las lluvias en el valle del río Magdalena, cuando el sol pasa al hemisferio austral, en septiembre, Codazzi dice:

"Es sabido que la causa de los vientos está en la diferencia de temperaturas de dos países vecinos, lo cual produce una ruptura de equilibrio entre las capas atmosféricas. Si dos columnas de aire tienen la misma temperatura y densidad en toda su altura, permanecen en equilibrio; pero si la tierra so. bre la cual reposan se calienta diferentemente, el equilibrio no puede menos de perturbarse generándose vientos que irán del país cálido al país frío, por la parte superior; y produciéndose por la inferior una corriente inversa que rasará la superficie de la tierra. Cuando el sol regresa del Trópico de Cáncer y ejerce su influjo sobre las selvas del bajo Magdalena, éstas se calientan: la corriente superior de aire rarefacto, se dirige hacia el mar, y la inferior debería bañar el alto Magdalena; pero no llega a él, porque se halla balanceado con el aire de ese país calentado por el sol en su paso hacia el ecuador. Mas como dicho astro al llegar a éste, en su paso al hemisferio austral, calienta los países situados en la vertical de los puntos que recorre, las corrientes superiores se dirigen en consecuencia hacia el $\mathbf{S}$. y las frías hacia el N., determinando las lluvias de octubre y noviembre, que suelen pro longarse también hasta mediados de diciembre".

Después de la muerte de Codazzi y de la terminación de la Comisión Corográfica, el doctor Liévano, como ya se dijo, quedó en el Observatorio Nacıonal y practicó allí observaciones meteorológicas hasta 1872 , coincidiendo su trabajo con el del doctor Juan de Dios Carrasquilla, quien inició observaciones pluviométricas en 1866. De los datos meteorológicos tomados por el doctor Liévano no hemos tenido noticia; en cambio, los debidos al doctor Carrasquilla, se conservan, en su mayor parte, publicados en el periódico denominado "El Agricultor".

El doctor Carrasquilla fue un investigador infatigable por muchos años, y a su propia costa practicó observaciones meteorológicas en un observatorio de su propiedad y suministró datos preciosos para la determinación del clima de la altiplanicie de Bogotá.

La relativa fijeza del barómetro y la periodicidad de sus pequeñas variaciones, llamaron poderosamente la atención del doctor Carrasquilla; y al estudio de este fenómeno dedicó gran parte de su actividad científica.

Probablemente bajo la influencia de preocupaciones de la época, el doctor Carrasquilla atribuyó, al explicar la causa de las oscilaciones diurnas del barómetro, una importancia mucho mayor de la que tiene en realidad, a la acción atractiva del sol y de la luna. En un trabajo publicado en los "Anales de Ingeniería", bajo el título de "Datos para la Climatología en Colombia" dice:

"La regularidad misma de las oscilaciones horarias confirma suficientemente que la atracción solar es su causa, que este astro obra por atracción, por su masa, más que por sus propiedades caloríficas, sobre el peso de la atmósfera. Al medio día, cuando el sol está más cerca del ecuador terrestre, ejerce la mayor atracción sobre los puntos del globo situados en la línea equinoccial y a ambos lados de ella". (En lugar de "ecuador" y "línea equinoccial" ha debido decirse: "meridiano"); pero como 
su acción no es instantánea, a causa de la naturaleza gaseosa de la atmósfera, se tarda algunas horas en hacerse sensible, y el barómetro no marca la menor altura de la columna mercurial hasta las tres o las cuatro de la tarde, así como las mareas oceánicas se hacen sentir con algún atraso y en relación con la posición del lugar".

A la explicación del doctor Carrasquilla se pueden presentar las siguientes objeciones:

Primero. Las oscilaciones horarias del barómetro no están bajo la dependencia de la atracción lunar, porque dichas oscilaciones se efectúan, según las observaciones, sensiblemente a unas mismas horas, durante todo el año.

Segundo. Siendo así, las oscilaciones tampoco están bajo la dependencia de la atracción solar, porque, a la distancia que de este astro nos separa, ésta es menor que la de la luna.

Tercero. La explicación del doctor Carrasquilla no es suficiente para explicar la mínima, observada en las horas de la madrugada (1).

Estas objeciones pueden citarse a título de curiosidad, pues la causa única de las oscilaciones diurnas del barómetro es la variación de la temperatura. Kamz fue el primero que dio la explicación conveniente, con el objeto de no hacer intervenir las mareas atmosféricas en este fenómeno. No hay para qué atribuír la doble oscilación barométrica a las mareas, cuya influencia, en la presión atmosfé. rica es insignificante, según lo demostró Laplace.

En la última época de observaciones del doctor Carrasquilla, el Presbítero Dr. Joaquín Gómez Otero, practicó también, al mismo tiempo, observacio. nes meteorológicas en el Observatorio anexo al Seminario Conciliar. De los datos acumulados por el doctor Gómez Otero copiamos un cuadro, correspondiente a 1886 , que contiene el resultado anual de las indicaciones del barómetro, el termómetro, el sicómetro y el pluviómetro, sin que en él se hicieran las correcciones del barómetro.

Cuadro de las observaciones meteorológicas hechas en el Seminario Conciliar de Bogotá, en el año de 1886 por el Rector Joaquín Gómez Otero

\begin{tabular}{|c|c|c|c|c|c|c|c|c|}
\hline \multirow{2}{*}{ MESES } & \multicolumn{3}{|c|}{ Barómetro } & \multicolumn{3}{|c|}{ Termómetro } & \multirow{2}{*}{$\begin{array}{l}\text { Humedad } \\
\text { relativa }\end{array}$} & \multirow{2}{*}{$\begin{array}{l}\text { Lluvia en } \\
\text { milímetros }\end{array}$} \\
\hline & Máxima & Mínima & Media & Máxima & Mínima & $\overline{\text { Media }}$ & & \\
\hline & & & & Grados & Grados & Grados & & \\
\hline Enero...$\ldots \ldots \ldots \ldots$ & 0.5609 & 0.5551 & 0.5590 & 22.0 & 7.0 & 14.0 & 81 & 101.9 \\
\hline Febrero $\ldots \ldots \ldots \ldots \ldots$ & 0.5612 & 0.5544 & 0.5584 & 22.0 & 6.0 & 14.5 & 78 & 51.3 \\
\hline Marzo $\ldots \ldots \ldots \ldots \ldots$ & 0.5611 & 0.5570 & 0.5593 & 22.0 & 7.0 & 15.0 & 79 & 87.9 \\
\hline Abril $\ldots \ldots \ldots \ldots \ldots$ & 0.5608 & 0.5567 & .5 .5590 & 20.0 & 6.0 & 14.0 & 82 & 167.9 \\
\hline Mayo .... & 0.5692 & 0.5550 & 0.5593 & 20.5 & 8.0 & 14.0 & 83 & 143.6 \\
\hline Junio $\ldots \ldots \ldots \ldots \ldots$ & 0.5614 & 0.5577 & 0.5593 & 22.0 & 5.5 & 14.0 & 84 & 55.1 \\
\hline Julio $\ldots \ldots \ldots \ldots \ldots$ & 0.5612 & 0.5576 & 0.5597 & 21.0 & 8.5 & 13.5 & 83 & 87.1 \\
\hline Agosto $\ldots \ldots \ldots \ldots$ & 0.5612 & 0.5572 & 0.5596 & 21.0 & 8.0 & 14.0 & 81 & 115.2 \\
\hline Septiembre $\ldots \ldots \ldots \ldots$ & 0.5609 & 0.5569 & 0.5589 & 20.5 & 8.5 & 14.5 & 81 & 139.9 \\
\hline Octubre $\ldots \ldots \ldots \ldots \ldots$ & 0.5618 & 0.5577 & 0.5582 & 20.5 & 7.0 & 14.0 & 85 & 164.1 \\
\hline Noviembre $\ldots \ldots \ldots \ldots$ & 0.5606 & 0.5555 & 0.5585 & 20.5 & 9.0 & 14.0 & 84 & 122.1 \\
\hline Diciembre ........... & 0.5604 & 0.5563 & 0.5586 & 20.0 & 8.0 & 14.0 & 84 & 125.0 \\
\hline
\end{tabular}

Resumen anual: Barómetro-máxima, promedio mensual 0.5618; mínima, promedio anual 0.5544; media, promedio anual, 0.5591. Termómetro-máxima, promedio anual, $22^{\circ} 0$; mínima, promedio anual, $5^{\circ} 5$; media, promedio anual, $14^{\circ} 1$. Pluviómetro-lluvia dura nte el año, $1^{\text {m}} 3609$; humedad media, 82.

NOTA.-Se ignora la calidad de los instrumentos usados, lo mismo que los métodos que se emplearon. Este cuađro fue publicado en los "Anales de Instruccion Pública".

Hasta el año de 1893 practicó observaciones meteorológicas en el Observatorio Nacional, el señor don José M. González Benito, y de ellas se da una muestra en el cuadro correspondiente al año de

(1). En un opúseulo del Dr. Carrasquilla publicado en Bogotá, en 1897, con el título: "Memoria sobre las mareas atmosféricas o fluctuaciones de la presión", se sostuvo por este sabio naturalista, con profusión de argumentos, la tesis en cuestion, que no es otra distinta de la de Mutis, tan encomiada por Caldas.
1890, y que copiamos con el objeto de establecer parangón entre los métodos usados hasta 1893 y los que ha empleado, de ese año para acá, el doctor Garavito, actual Director del Observatorio.
En su trabajo el Dr. Carrasquilla muy eruditamente agoto is materia sobre este punto, y por ello en ediciones posteriores de esta Revista volveremos a tratar el punto y, aún, reproduciremos partes importantes de la "Memoria sobre las mareas atmosféripartes importantes de la "Memoria sobre las mareas atmosférilo que en realidad debe aceptarse.-Nota de la Direccín. 

de 1890

\begin{tabular}{|c|c|c|c|c|c|c|c|c|}
\hline \multirow{2}{*}{ MESES } & \multicolumn{3}{|c|}{ Barómetro } & \multirow{2}{*}{$\begin{array}{l}\text { Humedad } \\
\text { relativa }\end{array}$} & \multicolumn{3}{|c|}{ Termómetro } & \multirow{2}{*}{$\begin{array}{l}\text { Lluvia en } \\
\text { milímetros }\end{array}$} \\
\hline & Máxima & Mínima & Media & & Máxima & Mínima & Media & \\
\hline & & & & & Grados & & Grados & \\
\hline Enero ........ & 0.56174 & 0.55960 & 0.56076 & 72 & 18.58 & 8.78 & 13.18 & 178.9 \\
\hline Febrero ........ & 0.56200 & 0.56012 & 0.56106 & 68 & 17.69 & 8.43 & 13.06 & 076.7 \\
\hline Marzo $\ldots . . . \ldots$ & 0.56204 & 0.56020 & 0.56112 & 64 & 17.59 & 8.67 & 13.13 & 068.0 \\
\hline Abril $\ldots \ldots \ldots \ldots$ & 0.56256 & 0.56038 & 0.56147 & 77 & 17.68 & 10.18 & 13.93 & 198.6 \\
\hline Mayo .......... & 0.56265 & 0.56064 & 0.56164 & 77 & 17.75 & 10.18 & 13.96 & 131.8 \\
\hline Junio $\ldots \ldots \ldots$ & 0.56259 & 0.56073 & 0.56166 & 63 & 18.17 & 9.97 & 14.07 & 026.0 \\
\hline Julio .......... & 0.56255 & 0.56105 & 0.56180 & 67 & 17.38 & 8.90 & 13.14 & 045.7 \\
\hline Agosto ......... & 0.56263 & 0.56087 & 0.56175 & 67 & 17.10 & 8.30 & 12.70 & 094.5 \\
\hline Septiembre ..... & 0.56250 & 0.56066 & 0.56158 & 62 & 16.91 & 8.89 & 12.90 & 035.7 \\
\hline Octubre $\ldots \ldots \ldots$ & 0.56207 & 0.55997 & 0.56102 & 76 & 17.42 & 8.66 & 13.04 & 204.4 \\
\hline Noviembre ...... & 0.56163 & 0.55957 & 0.56060 & 77 & 17.36 & 9.44 & 13.40 & 216.3 \\
\hline Diciembre ...... & 0.56221 & 0.56001 & 0.56112 & 74 & 17.40 & 8.80 & 13.10 & 058.9 \\
\hline
\end{tabular}

Resumen anual: Barómetro, máxima, promedio anual, 0.56226; mínima, promedio anual, 0.56022 ; media, promedio anual, 0.56124 . Termómetro, máxima, promedio anual, $17^{\circ} 67$; mínima, promedio anual, $9^{\circ} 10$; media, promedio anual, $13^{\circ} 38$. Pluviómetro, lluvia durante el año, $1^{\mathrm{m}} 3355$; humedad media, 70.43 .

NOTA.-Este cuadro fue publicado en los "Anales de Instrucción Páblica". Las observaciones se hícieron con instrumentos del Observatorio.

Termina aquí la reseña histórica que se refiere a la marcha de los estudios meteorológicos en el país, haciendo notar que, ahora, cuando merced a la colaboración de los ilustrados Padres Agustinos de Barranquilla y de las estaciones meteorológicas de las Universidades de Antioquia y del Cauca, se puede organizar un servicio central de Meteorología; y que los conocimientos del doctor Garavito, su práctica y lo acertado de su dirección, harán que los estudios meteorológicos en Colombia se pongan a la altura de los llevados a cabo en otras Repúblicas de América.

\section{DISTRIBUCION DE LAS LLUVIAS EN LAS DIFERENTES REGIONES DEL PAIS}

En el croquis cartográfico (1) que acompaña al presente estudio, se encuentran marcadas, con tinta negra sobre fondo azul, las diferentes regiones que presentan características pluviométricas diferentes, y que merecen estudio especial, pues del conocimiento completo de tales características y de sus modificaciones, se deducirá el clima general de la República, junto con algún plan que guíe el Ministerio de Agricultura, en sus concesiones sobre terrenos baldíos y en sus disposiciones sobre irrigación y legislación de aguas.

Hasta ahora, por mil causas independientes de la voluntad del Supremo Gobierno, aún no se ha organizado un servicio meteorológico centralizado convenientemente y que se proponga obtener los datos apuntados arriba. Por eso esta parte del presente estudio adolece de indeterminaciones inevita-

(1). Por razones tipográficas se omite este croquis, que fi guro en los Anales del Segundo Congreso Cientifico Panamericano de Washington. bles, pues, en su desarrollo hemos tropezado con falta de observaciones ordenadas, precisas $y$, sobre todo, reducidas a un centro común. En la mayor extensión del país los resultados de las observaciones meteorológicas practicadas, se presentan aislados, esporádicamente dispersos, y en muchas ocasiones, ofrecen poco crédito. Sólo de Bogotá y de la Sabana de Bogotá, existe un acopio suficiente de datos pluviométricos fidedignos, que cubra un espacio de tiempo considerable; pues, aunque en algunas otras poblaciones, como Barranquilla, Popayán y Medellín, se han hecho observaciones regulares, éstas no son ni tan continuadas ni tan completas como las practicadas en Bogotá. Los datos que se refieren a otras regiones del país, como se acaba de decir, son muy escasos, $y$ en su mayor parte se deben a viajeros que han recorrido de prisa el territorio.

Los observatorios permanentes, dotados de pluviómetros, que actualmente funcionan en Barranquilla, Popayán y Medellín son: en Barranquilla, uno a cargo de los RR. PP. Agustinos; en Popayán, otro a cargo de un profesor francés que depende de la Universidad, y en Medellín, el Observatorio Meteorológico de la Universidad de Antioquia.

En términos generales, podemos describir las condiciones de humedad y de lluvia del territorio de la República, diciendo que la precipitación acuosa es considerable, como corresponde a una comarca situada en la zona tórrida, aunque en algunas localidades la precipitación anual es más bien escasa, bajando en ciertos puntos por debajo de $600 \mathrm{~mm}$., lo que parece poco para un clima tropical.

Son húmedas, con grandes precipitaciones casi continuas, las costas occidentales, sobre todo en la región comprendida entre los ríos Mira y Micay, por 
toda la hoya baja del Patía, y de los ríos Sanguianga e Iscuandé y la falda occidental de la Cordillera, hacia el occidente de Túquerres, Pasto y Popayán. Según estimaciones propias y del doctor Fortunato Pereira, la cantidad de lluvia en Altaquer, por ejemplo, pasa anualmente de tres metros. En Barbacoas no hay estación seca y en Tumaco llueve continuamente, con intervalos sólo de unos tres o cuatro días secos.

Se presentan también grandes precipitaciones anuales en la hoya del río Atrato, por todo el centro del Chocó, en la vertiente N. de la Sierra Nevada de Santa Marta, en la hoya del río Zulia y en las regiones de los grandes ríos, afluentes del Amazonas, más hacia el sur del río Ariari. En la falda septentrional de la Sierra Nevada de Santa Marta, en la comarca que derrama sus aguas al lado de Maracaibo y en las costas sobre el Pacífico, las abundantes lluvias y la carencia de una estación seca definida pueden ser atribuídas a los vientos alisios reinantes; como se ve por el hecho de que, cuando las montañas se alejan de la costa o se hacen más bajas, disminuyen las precipitaciones atmosféricas hasta por debajo de $500 \mathrm{~mm}$. por año. Así, pues, los valles formados por las cordilleras interiores, presentan peculiaridades locales que dependen, entre otras, de esta circunstancia. Generalmente las vertientes meridionales de los valles, al norte de la República ofrecen la característica de una precipitación escasa, como sucede en la vertiente S. E. de la Sierra Nevada de Santa Marta, en la hoya del río César, en los alrededores de Riohacha y en toda la extensión de la Península de la Guajira.

Desde $1^{\circ}$ hasta $12^{\circ}$ de latitud norte no son iguales las estaciones, es decir, las épocas de sequedad y de lluvia, por cuanto influye la latitud así:

En la región comprendida, poco más o menos, entre $\operatorname{los} 8^{\circ}$ de latitud norte y el ecuador, hay dos estaciones lluviosas y dos de sequía, mientras que más al norte no hay más que una estación seca y otra de lluvias. Esto, por supuesto, no es general, ya que en la vecindad del ecuador la fijeza relativa de las estaciones depende, fuéra de las variaciones de las líneas isotermas y de los movimientos de la zona de calmas, de las condiciones peculiares de cada localidad.

En Bogotá, a $\operatorname{los} 4^{\circ} 36^{\prime}$ de latitud norte, las estaciones secas duran de enero a febrero y de junio a septiembre, correspondiendo los máximos de lluvia a abril y a noviembre (o a octubre). En Medellín, a $\operatorname{los} 6^{\circ} 8^{\prime}$, la estación más seca es la correspondiente a enero y febrero, siendo mayo y octubre los meses de las grandes lluvias. En Cartagena, a los $10^{\circ}$ $25^{\prime}$ de latitud, cesan casi completamente las lluvias de enero a abril, extendiéndose la estación seca de diciembre a mayo, o sea por espacio de cinco meses. La época de lluvias tiene dos máximos, uno a fines de mayo $y$ otro en octubre.

Teniendo cuenta de las condiciones locales, se puede decir que en las altiplanicies de Cundinamarca y Boyacá, y en la región central del valle del
Magdalena, se presentan dos estaciones lluviosas: la de marzo, abril y mayo y la de octubre, noviembre $y$ diciembre. Los vientos que corren por sobre los Llanos de Casanare modifican sensiblemente estas estaciones: como sucede, por ejemplo, en Chocontá, lugar al norte de Bogotá, donde llueve poco en marzo y abril, con más persistencia en mayo y junio, mucho en julio $\mathrm{y}$ agosto $\mathrm{y}$ poco en septiembre, octubre y noviembre. En estos Llanos de Casanare, tal como sucede al norte, se presentan seis meses de sequía y seis de lluvia, cuya mayor intensidad coincide con el máximo de precipitación en Chocontá y otros lugares al norte, situados en valles secundarios de la Cordillera Oriental. En Cáqueza, población situada al S. E. de Bogotá, se hace sentir de parte de los Llanos de San Martín, la misma influencia que las llanuras de Casanare ejercen sobre la precipitación acuosa, en lugares próximos a la falda oriental de la Cordillera.

En los Llanos de las riberas del Meta y del Alto Orinoco se presentan dos estaciones claramente marcadas; extendiéndose la estación húmeda de fines de abril a fines de octubre; en tanto que al pie de la Cordillera, del río Ariari hacia el sur, llueve abundantemente casi todo el año, caracterizándose la región por extensísimas selvas, grandes ríos, y una precipitación abundante que, según Codazzi, no puede bajar de 2.50 a 3.00 metros por año. De estas regiones dice Felipe Pérez:

"Los vientos alisios del S. E., que comienzan a soplar cerca del paralelo de $30^{\circ}$ a $35^{\circ}$ S., también atraviesan oblicuamente el Atlántico e inciden perpendiculares sobre la costa suramericana, que se extiende desde el Cabo de San Roque hasta el Cabo de Hornos, penetrando en el interior cargados de nubes y nieblas, de las cuales se desprenden antes de pasar por encima de los Andes. La cantidad de agua que transportan a aquellos países de estupenda fertilidad, puede calcularse por la que los ríos Plata y Amazonas devuelven al océano. En suma la tierra no presenta entre los trópicos ninguna región, que como éstas, tenga delante de sí y bajo el dominio de los veinte alisios, una extensión igual de mar; de donde resulta que no hay en el mundo país intertropical tan profusamente dotado de ríos como la vasta hoya del Amazonas".

"Los dos sistemas de vientos, el del N. E. y del S. E. coinciden en el interior de la América del Sur, entre el Ecuador y el istmo del Darién. En este lugar reinan las calmas y los grandes aguaceros".

"Las circunstancias mencionadas y otros agentes meteorologicos dividen las estaciones, en la parte septentrional de la América del Sur, en seis meses de aguaceros constantes y seis meses de tiempo sereno".

"No sucede así en la hoya del Amazonas, y menos todavía en el Caquetá, puesto que en él caen, durante algunos meses del año, continuos aguaceros, y lluvias ocasionales en los restantes, tanto por la configuración de las cordilleras de los Andes, cuanto porque la mayor parte de los terrenos bajos se encuentra en la zona de las calmas". 

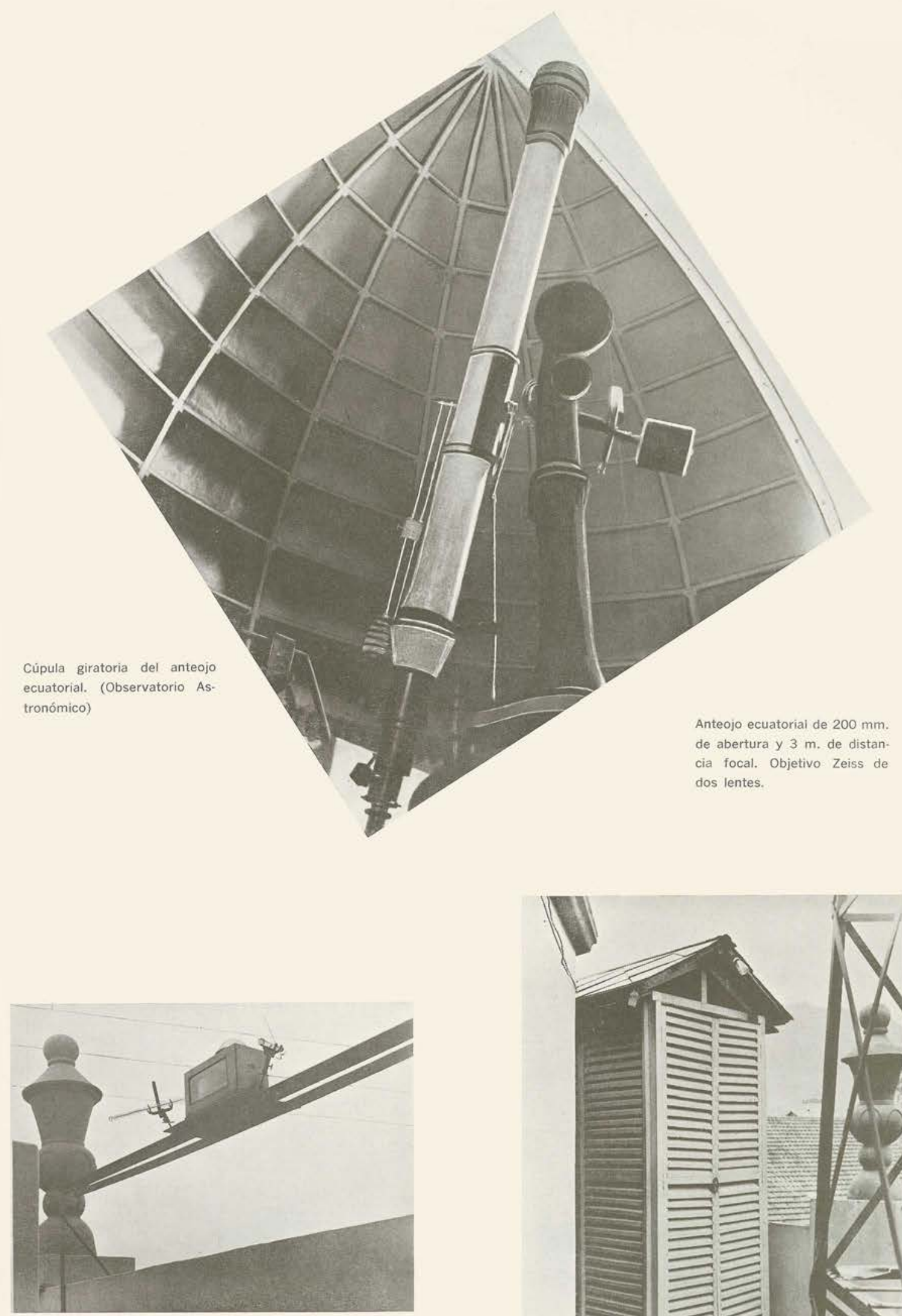

Actinómetro registrador Fuess, con termómetros conju. gados. (Azotea del Observatorio Astronómico).

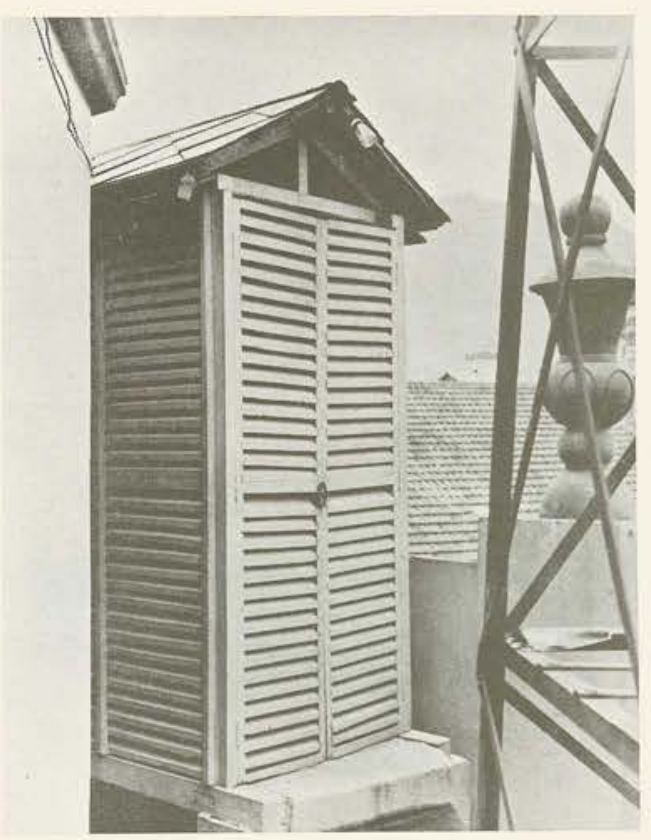




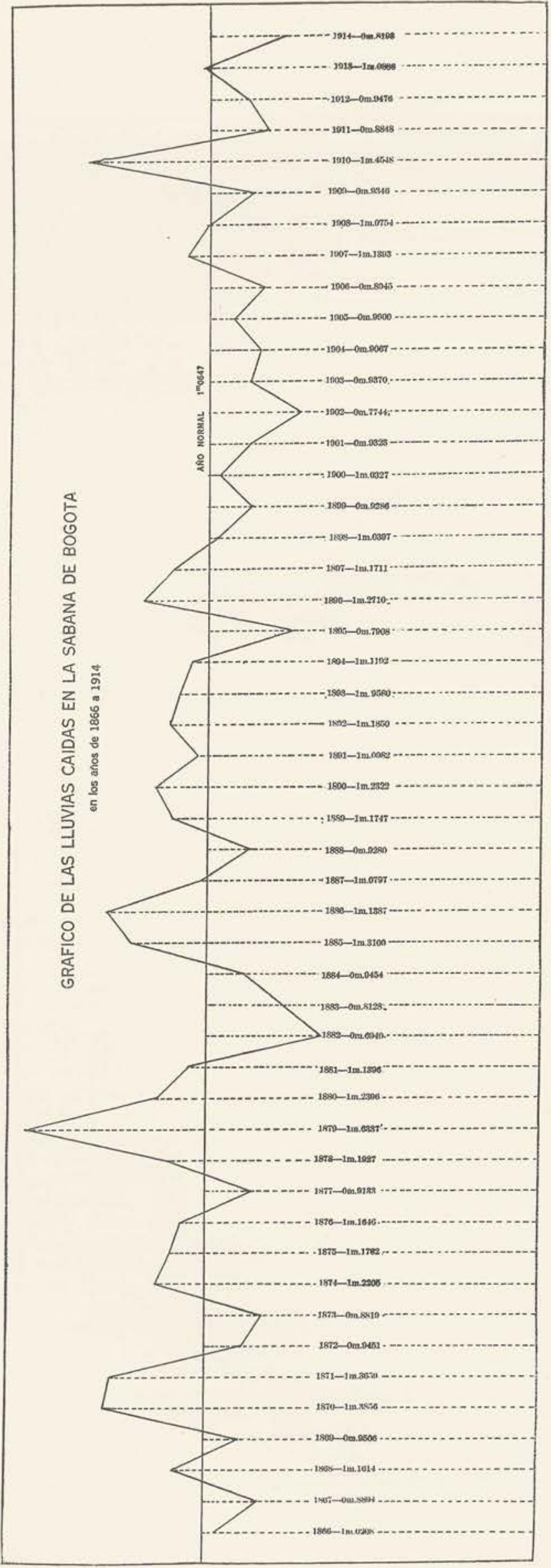

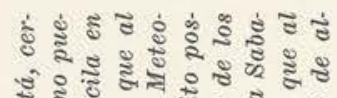

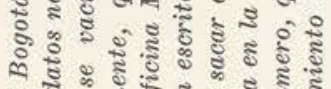
ษ

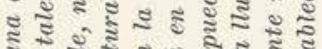

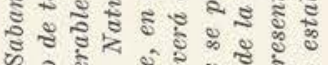

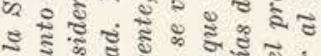
ษ

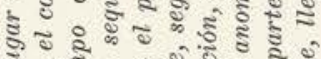
₹

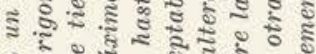

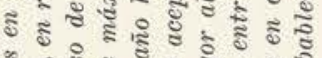

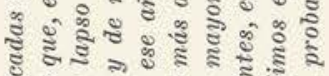

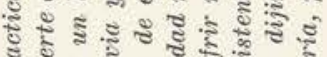
ำ ริ

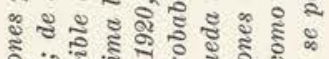

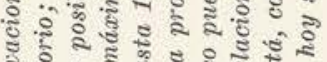

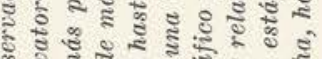

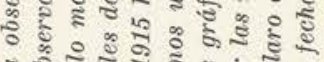

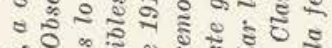

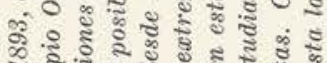

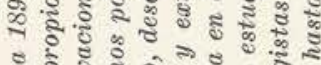

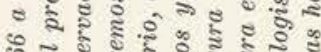

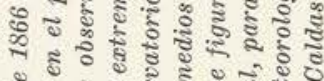
ะ कิ

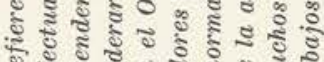

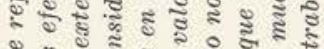

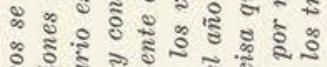

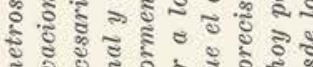

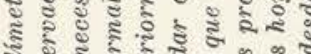

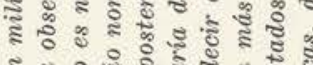

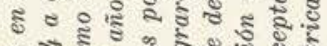

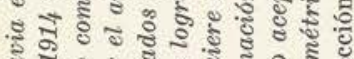

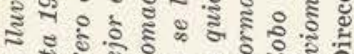

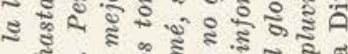
ะ

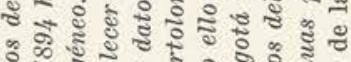

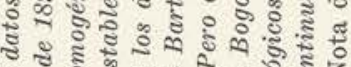

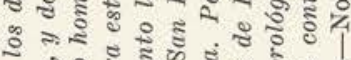
\&ัฐ

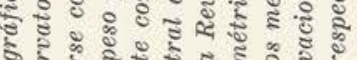

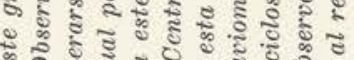

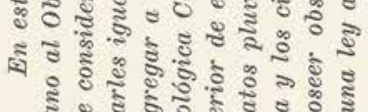
ฐ 
"Es bien sabido que las causas de los vientos son un efecto de la diferencia de temperatura de dos puntos próximos entre sí, pues entonces se establece una corriente inferior, que va de las partes más frías hacia los puntos cálidos, y otra superior que se dirige de éstos a las partes frías. De las altas cordilleras de Quito y Pasto bajan corrientes de aire, tanto del lado de occidente como del septentrión, hacia los terrenos que se encuentran cerca del ecuador, en la región de las calmas, calentados en extremo por los rayos perpendiculares del sol; ésta es la época del verano en Mocoa y sus inmediaciones, época de fuertes vientos que coincide con los meses de diciembre, enero y febrero, y una parte de marzo. Es en esa época, es decir, del 17 al 21 de marzo, que el sol pasa del hemisferio austral al hemisferio boreal, y su presencia, en el zenit de estos países calienta y enrarece continuamente la atmósfera; rómpese, pues, el equilibrio a cada momento; condénsanse los vapores suspendidos en el aire y caen lluvias copiosas, que en abril determinan las primeras crecientes de los grandes afluentes del Orinoco y del Amazonas. Los meses de mayo, junio, julio y agosto son la época de las fuertes lluvias en estos países. Del 18 al 28 de septiembre el sol ha pasado otra vez al hemisferio austral; entonces, en este mes y en los de octubre, noviembre y diciembre, hay lluvias interrumpidas por algunas semanas de buen tiempo, por razón de que los vientos de las cordilleras trastornan el equilibrio, soplan. do a veces en direcciones opuestas".

Concretándonos a Bogotá y a la Sabana de su nombre, podemos estudiar las precipitaciones acuosas anuales desde el año de 1866 hasta el año de 1914, como se ve en el dibujo adjunto, que figura con el título "Gráfico de las lluvias en la Sabana

Cuadro que manifiesta las cantidades de lluvia caídas en la Sabana de Bogotá, en los años transcurridos de 1866 a 1914

\begin{tabular}{|c|c|c|c|c|c|}
\hline Año & Cantidad & Año & Cantidad & Año & Cantidad \\
\hline & mm. & & $\mathrm{mm}$. & & $\mathbf{m m}$. \\
\hline $1866 \ldots$ & 1.0208 & $1883 \ldots \ldots \ldots \ldots \ldots$ & 0.8128 & $1899 \ldots \ldots$ & 0.9286 \\
\hline $1867 \ldots \ldots \ldots \ldots \ldots \ldots$ & 0.8894 & $1884 \ldots \ldots \ldots \ldots \ldots$ & 0.9454 & $1900 \ldots \ldots \ldots \ldots \ldots$ & 1.0327 \\
\hline $1868 \ldots \ldots \ldots \ldots \ldots \ldots$ & 1.1614 & $1885 \ldots \ldots \ldots \ldots$ & 1.3109 & $1901 \ldots \ldots \ldots \ldots$ & 0.9323 \\
\hline $1869 \ldots \ldots \ldots \ldots \ldots$ & 0.9506 & $1886 \ldots \ldots \ldots \ldots \ldots$ & 1.1387 & $1902 \ldots \ldots \ldots \ldots \ldots$ & 0.7744 \\
\hline $1870 \ldots \ldots \ldots \ldots \ldots$ & 1.3856 & $1887 \ldots \ldots \ldots \ldots \ldots$ & 1.0797 & $1903 \ldots \ldots \ldots \ldots \ldots$ & 0.9370 \\
\hline $1871 \ldots \ldots \ldots \ldots \ldots$ & 1.3659 & $1888 \ldots \ldots \ldots \ldots \ldots$ & 0.9280 & $1904 \ldots \ldots \ldots \ldots$ & 0.9067 \\
\hline $1872 \ldots \ldots \ldots \ldots \ldots \ldots$ & 0.9451 & $1889 \ldots \ldots \ldots \ldots \ldots$ & 1.1747 & $1905 \ldots \ldots \ldots \ldots \ldots$ & 0.9900 \\
\hline $1873 \ldots \ldots \ldots \ldots \ldots$ & 0.8819 & $1890 \ldots \ldots \ldots \ldots \ldots$ & 1.2322 & $1906 \ldots \ldots \ldots \ldots$ & 0.8945 \\
\hline $1874 \ldots \ldots \ldots \ldots \ldots$ & 1.2205 & $1891 \ldots \ldots \ldots \ldots \ldots$ & 1.0982 & $1907 \ldots \ldots \ldots \ldots$ & 1.1393 \\
\hline $1875 \ldots \ldots \ldots \ldots \ldots \ldots$ & 1.1762 & $1892 \ldots \ldots \ldots \ldots \ldots$ & 1.1850 & $1908 \ldots \ldots \ldots$ & 1.0751 \\
\hline $1876 \ldots \ldots \ldots \ldots \ldots$ & 1.1646 & $1893 \ldots \ldots \ldots \ldots \ldots$ & 1.1580 & $1909 \ldots \ldots \ldots \ldots \ldots$ & 0.9346 \\
\hline $1877 \ldots \ldots \ldots \ldots \ldots$ & 0.9133 & $1894 \ldots \ldots \ldots \ldots \ldots$ & 1.1192 & $1910 \ldots \ldots \ldots \ldots \ldots$ & 1.4548 \\
\hline $1878 \ldots \ldots \ldots \ldots \ldots \ldots$ & 1.1927 & $1895 \ldots \ldots \ldots \ldots \ldots$ & 0.7908 & $1911 \ldots \ldots \ldots \ldots$ & 0.8848 \\
\hline $1879 \ldots \ldots \ldots \ldots \ldots$ & 1.6337 & $1896 \ldots \ldots \ldots \ldots \ldots$ & 1.2710 & $1912 \ldots \ldots \ldots \ldots \ldots$ & 0.9476 \\
\hline $1880 \ldots \ldots \ldots \ldots \ldots$ & 1.2396 & $1897 \ldots \ldots \ldots \ldots$ & 1.1711 & $1913 \ldots \ldots \ldots \ldots \ldots$ & 1.0886 \\
\hline $1881 \ldots \ldots \ldots \ldots \ldots$ & 1.1396 & $1898 \ldots \ldots \ldots \ldots \ldots$ & 1.0397 & $1914 \ldots \ldots \ldots \ldots \ldots$ & 0.8193 \\
\hline $1882 \ldots \ldots \ldots \ldots \ldots \ldots$ & 0.6949 & & & & \\
\hline
\end{tabular}

NOTA.-De estos años, el de mayor lluvia fue el de 1879, en que cayo la cantidad de 1 metro 633,4 mm., viniendo después el de 1910, con una cantidad de $1 \mathrm{~m}$. $455 \mathrm{~mm}$. (Fn este año se presentaron inundaciones en la Sabana de Bogotá $y$ en el valle del Magdalena). El año de mayor sequedad fue el de 1882, pues solamente cayeron 0 metros $695 \mathrm{~mm}$. Por consiguiente, los años de 1879 y 1882 marcan los límites extremos dentro de los cuales oscila la cantidad de agua caida en la Sabana de Bogotá.

de Bogotá, en los años de 1866 a 1914". En este dibujo se encuentran las cantidades de lluvia caídas, expresadas anualmente en milimetros, y figuradas por ordenadas a la escala de 1/10.

Los datos de 1866 a 1893 fueron tomados cuidadosamente por el señor doctor Juan de Dios Carrasquilla, en un lugar próximo a la ciudad de Bogotá, situado dentro de los límites de la altiplanicie, $\mathrm{y}$ en condiciones semejantes, de presión y temperatura, a las de Bogotá; en tanto que las correspondientes al intervalo comprendido entre $1894 \mathrm{y}$ 1914 se deducen de observaciones practicadas en el Observatorio, con un mismo pluviómetro que fue comparado últimamente con otro de tipo diferente.

Durante los veintisiete años anotados por el doctor Carrasquilla, el promedio anual es de $1^{\mathrm{m}} .1053$, en tanto, que de 1894 a 1914 este promedio es próximamente de $1^{\mathrm{m}} \cdot 010$. La diferencia apuntada puede atribuírse a condiciones locales o a diferencias ligeras en los instrumentos usados (no se sabe cuál fue el pluviómetro empleado por el doctor Carrasquilla). Parece que priva la primera causa, por cuanto el lugar de observación escogido por el doctor Carrasquilla queda en proximidad a la serranía occidental de la altiplanicie, donde la condensación es un poco mayor que en Bogotá.

De todas maneras, la diferencia es insignificante y demuestra que, para cualquier lugar de la altiplanicie, el promedio anual de la precipitación es próximamente de un metro, y que la poligonal trazada, desde 1866 hasta 1914, corresponde bastante bien a las cantidades de agua caídas en los lugares situa- 


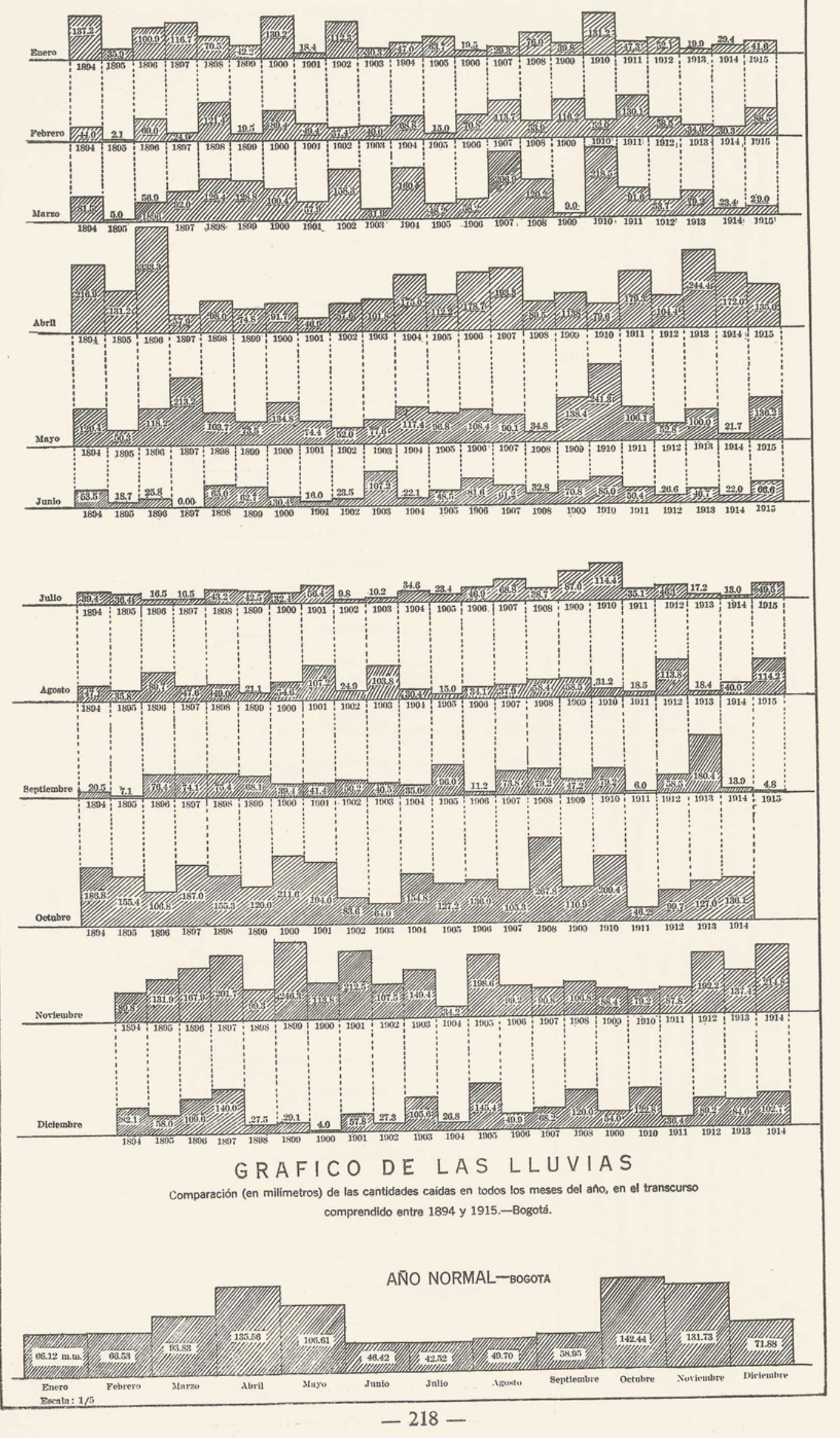


dos en condiciones análogas, como Tunja, Ubaté, Sogamoso y demás poblaciones colocadas en la parte central de la Cordillera Oriental.

En el cuadro respectivo, se pone de manifiesto que durante el lapso comprendido entre 1866 y 1914 (un espacio de 48 años), el año más seco en la Sabana de Bogotá, es decir, el de menos precipitación, fue el de 1882, al cual corresponde una cantidad caída de 0.m. 695 y el de mayor lluvia, el de 1879, con una precipitación de $1 \mathrm{~m}$. 635. De suerte que la diferencia de $0 \mathrm{~m} .939$ es casi una vez y media el mínimum registrado.

Así, pues, los límites entre los cuales oscila la cantidad de lluvia registrada anualmente, se encuentran tan separados que, juntamente con la ninguna periodicidad (como se ve observando el gráfico respectivo), no permiten preveer nada al respecto. A un año seco sucede otro más seco, u otro húmedo; pueden presentarse dos años seguidos con precipitación abundante, o un año muy seco y otro, a continuación de lluvias excepcionales, sin que en esto medie ley de ninguna clase, ni se encuentre período definido. Por estas razones la prevision del tiempo en las altiplanicies y vertientes de la Cordillera, que se encuentren en condiciones semejantes a las de la Sabana de Bogotá, parece prácticamente imposible.

Comprueba esta afirmación el hecho de que registrando en los cuarenta y ocho años dichos, las variaciones de la actividad solar, no se encuentre correspondencia entre los máximos y mínimos de ésta (mayor o menor superficie manchada del sol), con las precipitaciones acuosas máximas o mínimas.

Según Flammarion, en los años de 1872, 1883, 1893 y 1904, que corresponden al ciclo hallado, de diez a doce años, se debe registrar el máximo de actividad solar, con mínimas correspondientes a los años de 1889 y 1901. Ahora bien, tales máximos de actividad no coinciden en manera alguna, con las mayores precipitaciones, ni los períodos de mínima con los años de menor precipitación; de suerte que, por lo menos, en las altiplanicies de la zona intertropical americana, nada tienen que ver las manchas solares con la precipitación anual. Esta es enteramente caprichosa y no se sujeta a ley ninguna conocida. Ni siquiera se comprueba la existencia del ciclo de Bruckner, de treinta y cinco años.

Conviene advertir que los años de más grandes lluvias y los de mayor sequedad, registrados en la Sabana de Bogotá, concuerdan con los mayores inviernos (épocas de lluvia) y con los grandes veranos (épocas secas) que se registran en los valles grandes, situados entre las cordilleras principales, tales como el valle del Magdalena, en su parte central. En los años de 1879 y 1910 ocurrieron grandes inundaciones, tanto en la Sabana de Bogotá, como en el Tolima y en el Bajo Magdalena.

Considerando ahora la distribución de la lluvia en todos los meses del año, veamos los dibujos que, bajo el título de "Gráfico de las lluvias en Bogotá", ponen de manifiesto las cantidades caídas mes por mes, desde 1894 hasta 1915.

Cuadro que manifiesta las cantidades de lluvia caídas en Bogotá en los años de 1894 a 1915

\begin{tabular}{|c|c|c|c|c|c|c|c|c|c|c|c|c|}
\hline Años & Enero & Feb. & Marzo & Abril & Mayo & Junio & Julio & Agosto & Sept. & oet. & Nov. & Dic. \\
\hline $1894 \ldots$ & .2 & 44.0 & .0 & & & & $x$ & 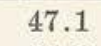 & 0.6 & 186.8 & 89.8 & 82.1 \\
\hline 1895. & & & & & & & & & & & & 58.0 \\
\hline 1896. & 00.9 & 69.0 & 56.9 & 33.3 & 2 & & & 89.7 & 76.4 & 106.8 & 167.9 & 109.6 \\
\hline $1897 \ldots$ & 116.7 & 24.4 & 92.0 & & 2 & & 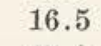 & 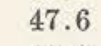 & .1 & .0 & 201.7 & 140.0 \\
\hline $1898 .$. & & 121.4 & 129.4 & & & & & & & 55.3 & & 27.5 \\
\hline $1899 \ldots$ & 42.2 & & & & & & & & & 120.0 & & 29.1 \\
\hline $1900 \ldots$ & 130.2 & 89.4 & 1 & & & & & & 4 & 211.6 & & 4.0 \\
\hline $1901 \ldots$ & & & & & & & & & & & & 57.8 \\
\hline $2 \ldots$ & & & & & & & 9. & & & & & 27.3 \\
\hline $1903 .$. & & & & & & & & & & 64.0 & 149.4 & 105.6 \\
\hline $1904 \ldots$ & & 6 & 16 & & 4 & & ? & & & 154.8 & & 26.8 \\
\hline .. & 6 & & & & & & & & & 12 & & 145.4 \\
\hline $1906 \ldots$ & & 70. & & & & & & & & & & 49.9 \\
\hline & & & & & & & & & & & & \\
\hline $1908 .$. & 76.0 & 5 & 0.2 & 8 & 34.8 & 32.8 & 3 & 4 & 2 & .8 & 106.8 & 120.0 \\
\hline $1909 \ldots$ & & 116.2 & & 113.8 & & & & & & & & 54.0 \\
\hline & 132.2 & & & & & & & & 79.2 & 209.4 & 79.2 & 122.8 \\
\hline $1911 \ldots$ & 47.3 & 130.1 & 91.6 & 179.3 & 106.1 & 4 & .1 & 5 & 6.0 & 46.2 & 87.8 & 36.4 \\
\hline $1912 \ldots$ & 52.1 & & & 104.4 & & & & 113.8 & 58.5 & 99.7 & 192.2 & 89.2 \\
\hline 1913.. & 19.9 & 0 & .2 & & 100.0 & & 17.2 & 18.4 & 180.4 & & & 84.0 \\
\hline $1914 \ldots$ & 29.4 & 30.3 & 23.4 & 172.0 & 21.7 & 22.0 & 13.0 & 40.0 & 13.9 & 136.1 & 214.8 & 102.7 \\
\hline $1915 \ldots$ & 41.6 & 86.5 & 29.0 & 135.0 & 136.2 & 66.6 & 49.5 & 114.4 & 4.8 & 130.0 & $\ldots$. & $\ldots$ \\
\hline
\end{tabular}

En esos dibujos las ordenadas representan con la escala de 1/10 la lluvia mensual, en milímetros, registrada en el Observatorio de Bogotá.
Como las cantidades correspondientes al mismo mes, se corresponden en línea vertical, es fácil, a simple vista, comparar un año cualquiera con el 
normal, cuya poligonal encabeza el cuadro. El año normal presenta dos estaciones lluviosas y dos secas.

De la inspección de las figuras aparece que es raro el año que en la distribución de la lluvia se aproxime al normal. A veces sucede que se presenta un avance en las estaciones, otras veces que ocurre un retardo y otras, como en el año de 1900 (en que los meses de marzo, abril y mayo fueron de menor lluvia que los restantes del año) en que se in vierten las estaciones y se altera completamente el orden de los fenómenos meteorológicos.

Para juzgar de las alteraciones que pueden ocurrir en la distribución mensual de la lluvia, se di- bujó el "Gráfico de las lluvias (comparación en milímetros) de las cantidades caídas en todos los meses del año, en el transcurso comprendido entre 1894 y 1915”. (Página 218).

En el dibujo en cuestión, aparecen claramente marcadas las cantidades caídas en los doce meses del año, desde 1894 a 1915 ; allí se echa de ver que, si en las precipitaciones anuales hay irregularidad manifiesta, en las precipitaciones mensuales también se presentan irregularidades notables. Por ejemplo, durante los veintiún años a que se refiere el cuadro, el mes de abril varió de un mínimo de $46.9 \mathrm{~mm}$. (en 1901) a un máximo de $333.3 \mathrm{~mm}$. (en

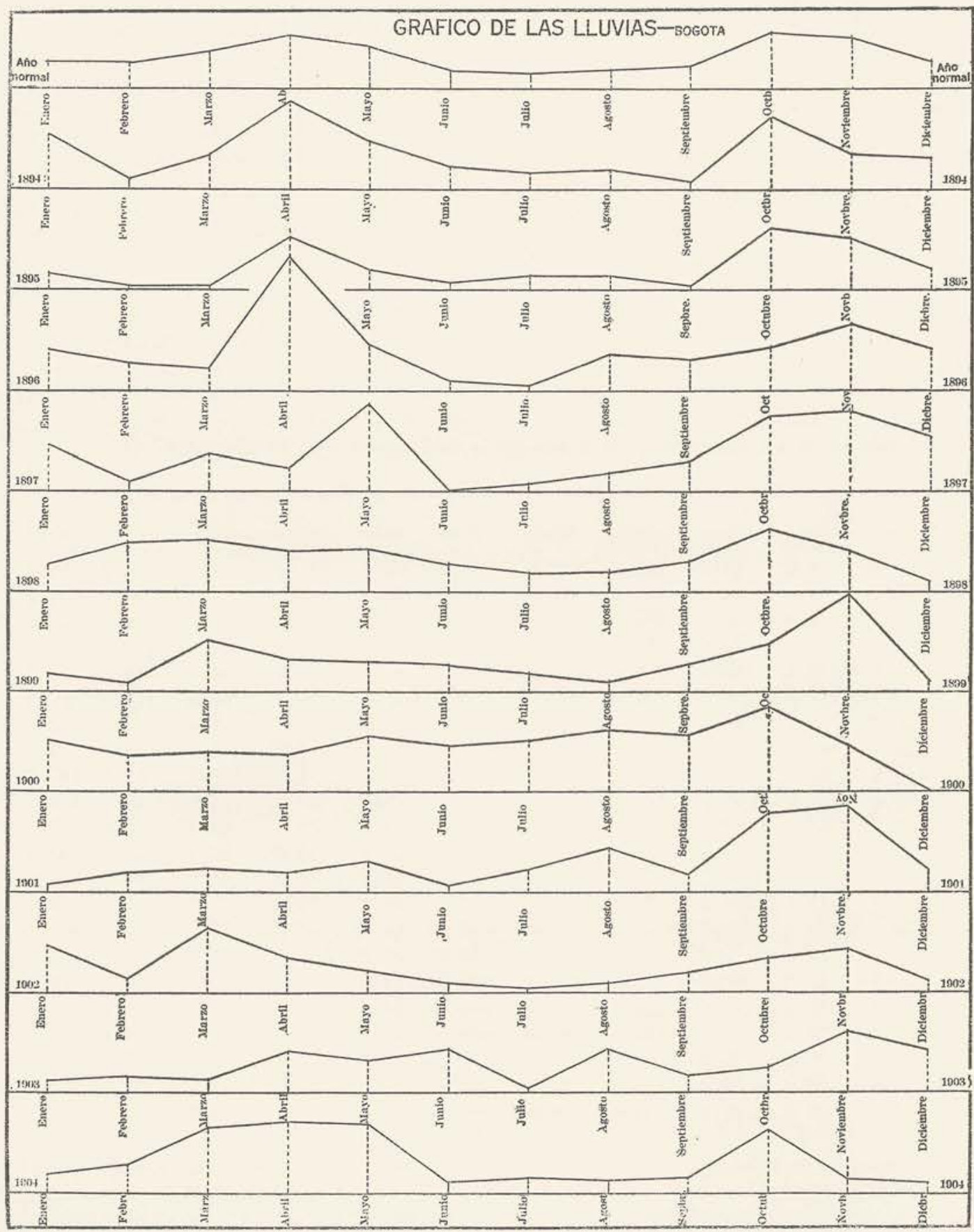




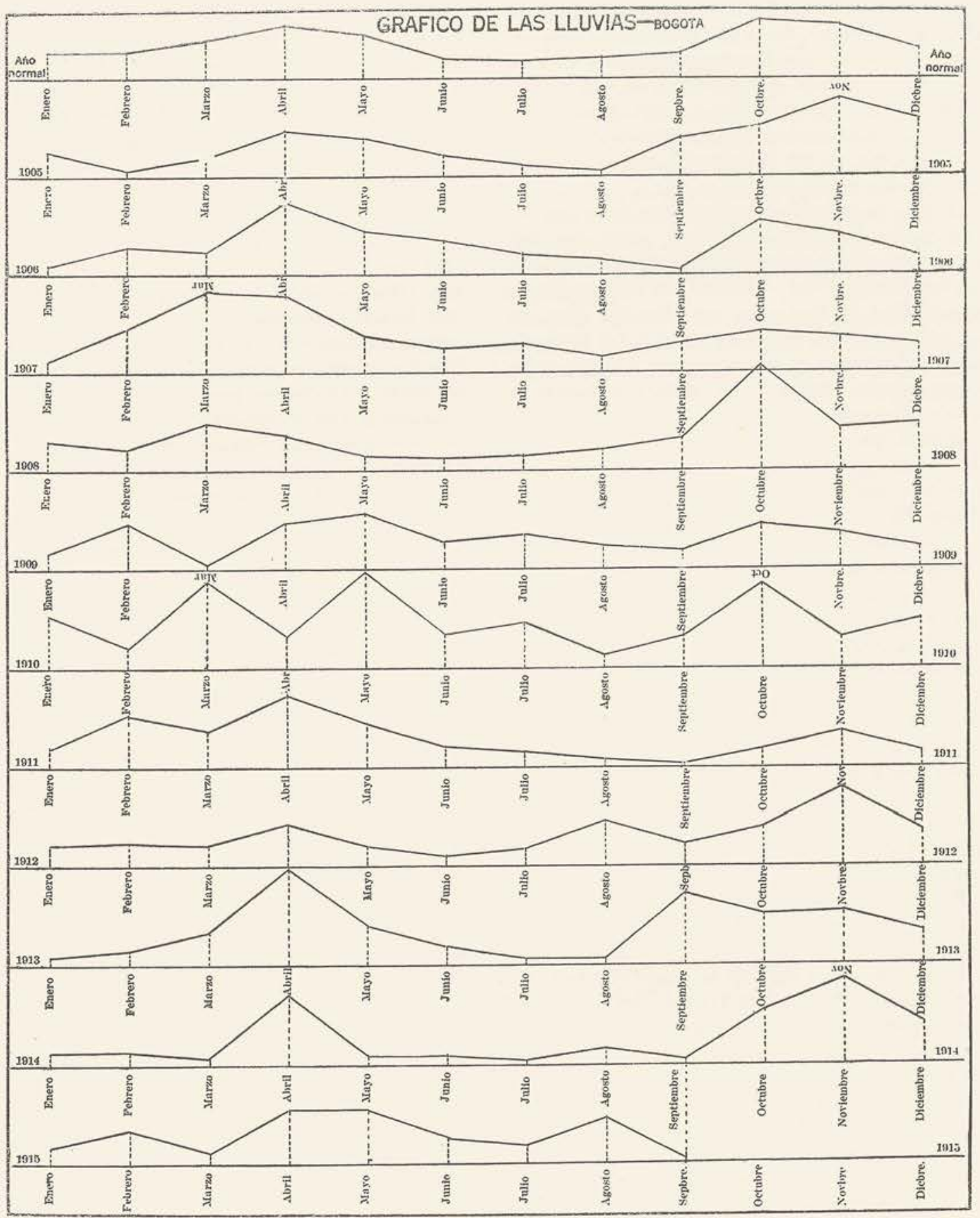

1896) ; el mes de junio varió de un máximo (107.2 mm.) en 1903 a cero, en 1897. Las oscilaciones mensuales pueden, pues, ocurrir entre los dos límites extremos : $0 \mathrm{~mm}$. y $333.3 \mathrm{~mm}$. Dentro del mismo mes ocurren alteraciones frecuentes, presentándose la lluvia en grandes aguaceros (se han registrado aguaceros torrenciales que han pasado de $50 \mathrm{~mm}$.) $o$ en forma de lloviznas continuas.

Los hechos consignados hasta ahora demuestran, a nuestro modo de ver, que las previsiones que se refieren a la lluvia son infundadas. El mismo doctor Carrasquilla, quien había llegado a creer posible la previsión, por medio de un estudio detenido de cada localidad, de la distribución de la lluvia, se convenció, después de treinta años de observaciones, de que esto era casi imposible. En 1894 escribia:

"Hasta hoy, por las observaciones practicadas, por el estudio de los cuadros meteorológicos, podemos decir que hay en el año dos estaciones lluviosas y dos secas, y explicarlas; pero de ahí no pasan nuestros conocimientos; al tratar de aplicarlos a determinado día, fracasamos. Para ello sería preciso estudiar mejor la meteorología de cada lugar; fijar con todo rigor la dirección e intensidad de cada viento local, $y$ tener para ello en cuenta to- 
das las circunstancias del meteoro que se estudia.

"Hay, sin embargo, datos que sirven para simplificar el problema y que tienden por consiguiente a su resolución. Hemos demostrado con observaciones precisas, que las variaciones de la presión no influyen directamente sobre las lluvias; podemos, pues, prescindir de las variaciones de la presión para el estudio de las lluvias.

"Las fases de la luna, que tánto han dado que decir, no ejercen la menor influencia sobre las lluvias, como ya varias veces lo hemos demostrado. En efecto, examinando los cuadros de observaciones meteorológicas, en que están anotados los días de lluvia y su cantidad, por una parte, y las fases de la luna, por otra, no es posible hallar ninguna relación que permita atribuír a la influencia lunar la causa de las lluvias.

"Podemos, pues, suprimir la influencia lunar en el estudio del problema de las lluvias, y concentrar toda la atención a los vientos, que a su turno son manifestaciones de las diferencias de temperatura que se hacen en la atmósfera. Este es el punto esencial, aquí está la solución del problema. Mientras no se hagan numerosos los observatorios meteorológicos, no se puede esperar nada, porque las observaciones aisladas no permiten llegar a un resultado satisfactorio. Conociendo la dirección del viento en distintas localidades, situadas a poca distancia unas de otras, se podría esperar este resultado; en una sola estación es casi imposible".

Se puede avanzar un poco más la tesis del doctor Carrasquilla, observando que, como la presión atmosférica varía muy poco y el barómetro no sirve, lo mismo que en las zonas templadas, para anunciar cambio de tiempo, en la zona ecuatorial quedan generalmente indeterminadas las relaciones de humedad y condensación en las altas regiones de la atmósfera.

La extremada movilidad de la atmósfera se hace sensible hasta en un recinto cerrado, en donde el aire esté aparentemente en reposo; allí un rayo luminoso pone de manifiesto partículas ligeras en suspensión, que se mueven en todos sentidos con velocidades variables, según corrientes del fluído, que obedecen a variaciones insignificantes de pre. sión, volumen y temperatura. Estas variaciones son pequeñísimas $\mathrm{y}$, sin embargo, pueden influír en la formación y la condensación del vapor de agua. Así, pues, aun en el caso de una atmósfera aparentemente en reposo, cuando el anemómetro no acusa la más ligera brisa, deben existir diversas corrientes que determinan fenómenos de condensación o evaporación, independientes de causas que se puedan registrar con nuestros instrumentos meteorológicos.

Además, una causa que produce un efecto determinado, como el caldeamiento por los rayos solares de una porción definida de la atmósfera, que origina movimientos del aire circunvecino hacia dicha región, puede producir un efecto contrario, si se interpone la masa de nubes debida a la condensación de los vapores, por enfriamiento en una region más alta. De manera que, aun conociendo sobre la su- perficie terrestre la velocidad y dirección de las corrientes aéreas, en lugares próximos, como lo quiere el doctor Carrasquilla, nada se puede adelantar.

Por la experiencia que se tiene del clima de la altiplanicie de Bogotá, podemos afirmar que sólo es posible conocer la distribución general de las lluvias (la que figura en los gráficos), siguiendo los movimientos del paralelo de mayor temperatura.

En la zona intertropical el aire caldeado por el sol, cuyos rayos inciden normalmente, se halla en continuo ascenso, y es reemplazado por el más frío que afluye de los hemisferios laterales, formando una faja, movible con el paralelo de mayor temperatura, y al cual acompaña en su oscilación anual. Esa faja o zona de calmas, como se quiera llamar, es de lluvia permanente, porque el vapor de agua que contiene el aire se condensa hasta la saturación, al ascender a las altas regiones de la atmósfera, por el enfriamiento que allí sufre. El movimiento anual de esta zona de lluvias determina las estaciones, ya indicadas someramente, en las varias regiones del pais, con las modificaciones anotadas, que se deben a influencias locales.

Siguiendo esta idea primordial y adaptándola a las condiciones locales de Bogotá, el actual Director del Observatorio, doctor Julio Garavito A., dio la explicación completa del fenómeno de las cuatro estaciones y de las irregularidades que éstas presentan en la Sabana, en un opúsculo que publicó en 1899, bajo el epígrafe de "Clima de Bogotá". Las observaciones practicadas desde entonces hasta la fecha, no han hecho sino comprobar lo afirmado allí por el doctor Garavito.

Por supuesto que, si es inútil pretender un cono. cimiento completo de la distribución de las lluvias y prever los cambios que ésta pueda sufrir, es conveniente conocer un promedio de las precipitaciones en cada región y las cantidades máximas y mí nimas que caractericen su régimen pluviométrico. Utilísimo sería, sin duda, para la agricultura conocer de antemano las épocas de verano o invierno, mas ya que esto no es posible, por lo menos, se debe tener una idea del clima de cada región, llevando un registro pluviométrico en varias regiones del país y una anotación de los vientos reinantes.

Si mes por mes se toman todos los datos recogidos y se colocan en la Carta de la República, es probable que muchas irregularidades queden explicadas dentro de un término de diez años. Ya se conoce completamente el clima de Bogotá, mas falta por determinar el del resto de la comarca, y el medio que indicamos para ello es el más sencillo.

La conducción de una estación pluviométrica es sencilla: puede encargarse de ella a un individuo cualquiera y no requiere mayor atención, sobre todo si se hace uso en ella de un pluviómetro registrador. Una estación pluviométrica debe componerse de un pluviómetro, un anemómetro y una veleta.

En el Observatorio de Bogotá se recibirían, una vez erigido en estación central, al establecerse este servicio meteorológico, los datos referentes a la cantidad de lluvia caída, dirección predominante 
del viento y velocidad media del mismo, datos provenientes de regiones diversas $\mathbf{y}$ sometidas a influencias locales distintas. Así, tal vez, se llegarían a conocer mejor las perturbaciones en la distribución de la lluvia.

Además de lo dicho, los datos pluviométricos prestan servicios importantes para elaborar los proyectos de irrigación, de acueductos, de canales, etc., en dondequiera que sea necesario conocer la cantidad media de lluvia, en cierto tiempo y las máximas precipitaciones.

Para terminar esta parte del presente estudio, indicamos las poblaciones de la República en donde convendría establecer estaciones pluviométricas, e insinuamos la mejor manera de organizar un Servicio Meteorológico centralizado.

En este sentido se podría, por medio de algún decreto orgánico, disponer :

Primero.-Que el Observatorio Nacional sea Estación Meteorológica central, provista de instrumentos registradores;

Segundo.-Que los Observatorios meteorológicos de Popayán, Barranquilla y Medellín envíen mensualmente a éste, los datos que recojan y la descripción de los aparatos usados;

Tercero.-Que se establezcan estaciones meteorológicas en los siguientes lugares (véase el mapa):
Cartagena, Santa Marta, Riohacha, Valledupar, Chiriguaná, Turbo, Quibdo, Magangué, Cucuta, Manizales, Puerto Berrío, Montería, Aicandi, Honda, Bucaramanga, Tunja, Arauca, Orocué, Támara, Girardot, Florencia, Ibagué, Neiva, Cartago, Cali, Buenaventura, Mocoa, Pasto, Túquerres, Barbacoas y Tumaco. (Estas estaciones se reparten así porque creemos que su situación relativa es conveniente, ya por cuanto presentan facilidades para el establecimiento de las estaciones, ya porque dan las condiciones locales de toda la región en donde se encuentran, $\mathbf{y}$

Cuarto.-Que en las estaciones pluviométricas presten el servicio los maestros de escuela, mediante un pequeño sobresueldo, y que la organización del Servicio Meteorológico quede a cargo del Ministerio de Instrucción Pública.

\section{FIJEZA RELATIVA DE LA PRESION ATMOS- FERICA - ALTIMETRIA POR MEDIO DEL BAROMETRO}

Para poner de relieve la diferencia esencial que existe entre las variaciones del barómetro en las zonas templadas y en la vecindad del ecuador, copiamos a continuación el cuadro siguiente, debido al doctor Carrasquilla :

Paralelo entre la presión de Bogotá y la de París en 1897

\begin{tabular}{|c|c|c|c|c|c|c|c|c|}
\hline \multicolumn{4}{|c|}{ BOGOTA } & \multicolumn{5}{|c|}{ PARIS } \\
\hline MESES & $\begin{array}{c}\text { Término } \\
\text { medio }\end{array}$ & Mínimo & Máximo & Diferencias & $\begin{array}{c}\text { Término } \\
\text { medio }\end{array}$ & Mínimo & Máximo & Difereneias \\
\hline Enero ....... & 560.77 & 558.56 & 563.28 & 4.72 & 753.98 & 737.07 & 770.82 & 33.75 \\
\hline Febrero .... & 561.17 & 560.10 & 563.45 & 3.35 & 762.58 & 742.18 & 774.49 & 32.23 \\
\hline Marzo ....... & 560.78 & 560.10 & 563.28 & 4.82 & 754.11 & 744.24 & 763.10 & 18.86 \\
\hline Abril ...... & 561.15 & 559.19 & 563.58 & 4.29 & 754.82 & 732.23 & 766.74 & 34.51 \\
\hline Mayo ...... & 561.12 & 559.18 & 563.68 & 4.40 & 756.63 & 744.25 & 766.50 & 22.25 \\
\hline Junio ...... & 561.39 & 559.23 & 563.98 & 4.35 & 758.92 & 752.63 & 763.33 & 14.40 \\
\hline Julio ...... & 561.27 & 559.19 & 563.32 & 4.13 & 758.49 & 749.35 & 765.57 & 16.22 \\
\hline Agosto ...... & 561.41 & 559.78 & 563.98 & 4.20 & 756.34 & 749.84 & 760.57 & 10.73 \\
\hline Septiembre .. & 561.37 & 559.18 & 563.58 & 4.40 & 758.88 & 747.95 & 767.68 & 19.73 \\
\hline Octubre .... & 560.99 & 559.18 & 563.58 & 4.40 & 762.03 & 749.62 & 768.79 & 19.17 \\
\hline Noviembre ... & 560.20 & 559.03 & 561.88 & 2.85 & 763.29 & 745.82 & 774.54 & 28.72 \\
\hline Diciembre ... & 560.34 & 558.63 & 562.48 & 3.85 & 753.29 & 746.94 & 771.52 & 24.58 \\
\hline Promedios ... & 560.99 & 559.14 & 563.29 & 4.15 & 757.78 & 745.17 & 768.13 & 22.95 \\
\hline
\end{tabular}

La simple inspección del cuadro anterior, llama la atención por las diferencias tan notables que presenta. Es por eso que el barómetro pierde, en la zona ecuatorial, su importancia como instrumento meteorológico y la gana como instrumento de ingeniería, máxime en países montañosos como Colombia. La altimetría por medio del barómetro de mercurio, del hipsómetro o del barómetro aneroide es mucho menos complicada, en las regiones situadas dentro de los trópicos, que en las regiones de las zonas templadas, donde las observaciones de altura deben ser siempre simultáneas. Así, pues, como lo había previsto Caldas, el estudio de las variaciones periódicas de la presión atmosférica tiene importancia capital para las medidas de las alturas, en las nivelaciones barométricas, que ordinariamente se emplean para los reconocimientos, pues la regularidad y falta de amplitud en la oscilación periódica de la presión atmosférica permite usar el barómetro como instrumento suficientemente exacto en gran número de aplicaciones de esta clase.

Por estas razones es que una de las principales preocupaciones del Observatorio ha sido determinar muy bien la curva indicadora de las dobles os- 


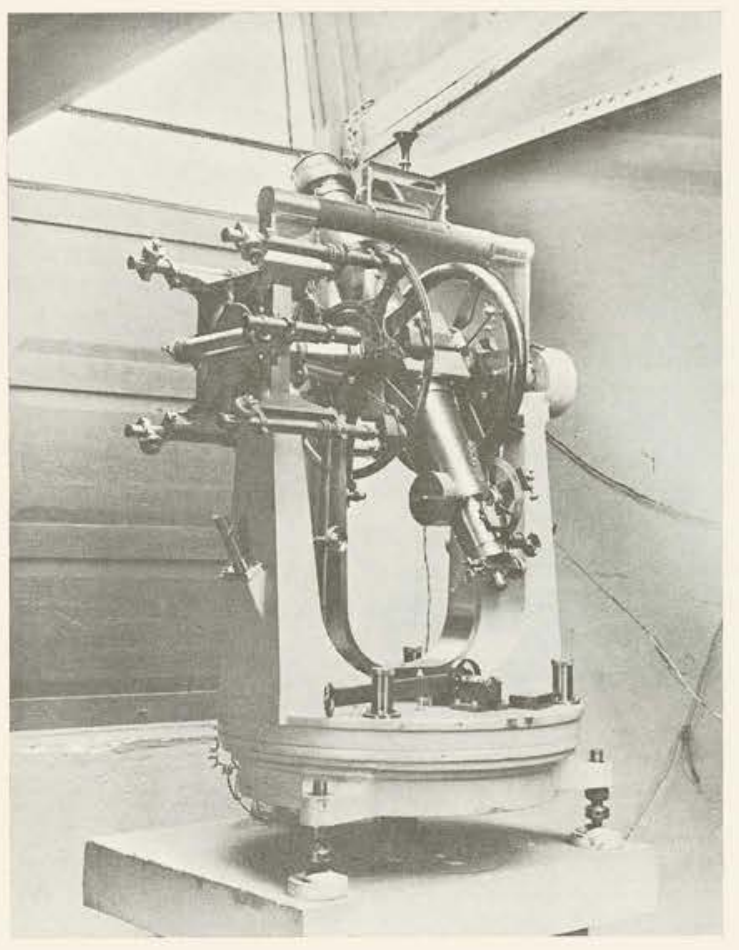

Circulo meridiano de "la Filotécnica" de Milán, de $80 \mathrm{~mm}$. de abertura y $90 \mathrm{~cm}$. de distancia focal con micrómetro impersonal (Casilla meridiana. Observatorio Astronómico)

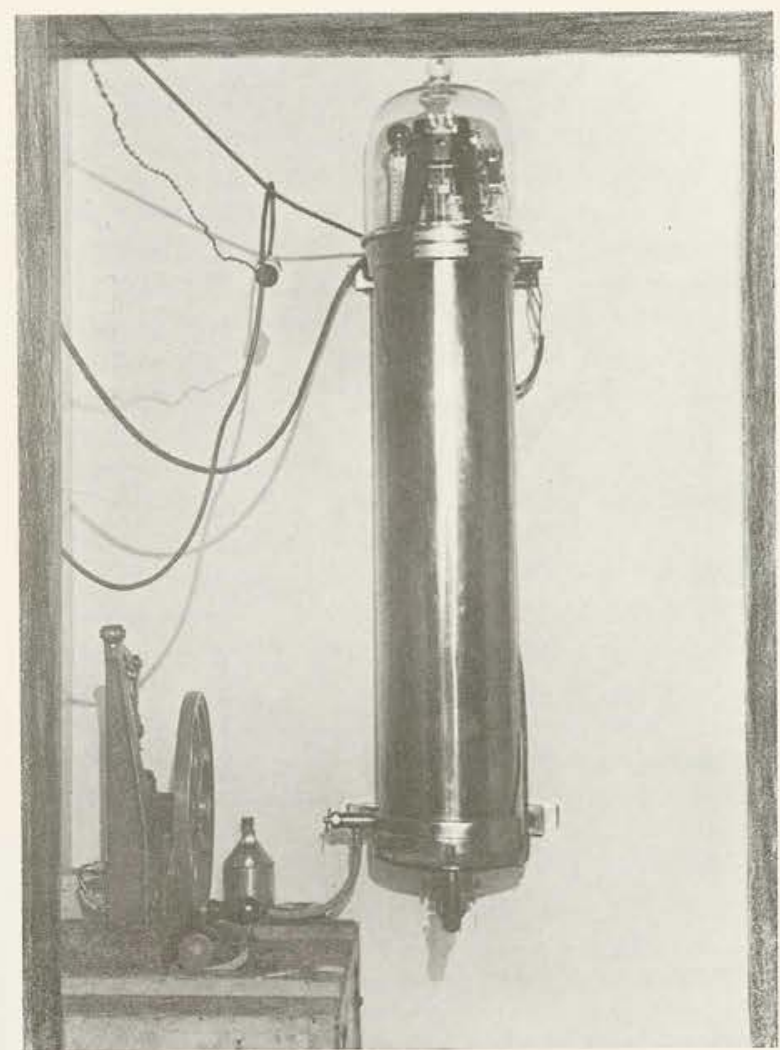

Péndulo libre, al vacío, de "Shortt", con sus accesorios. Este péndulo está conectado eléctricamente con el que se encuentra en la casilla meridiana. (Observatorio Astro. nómico)

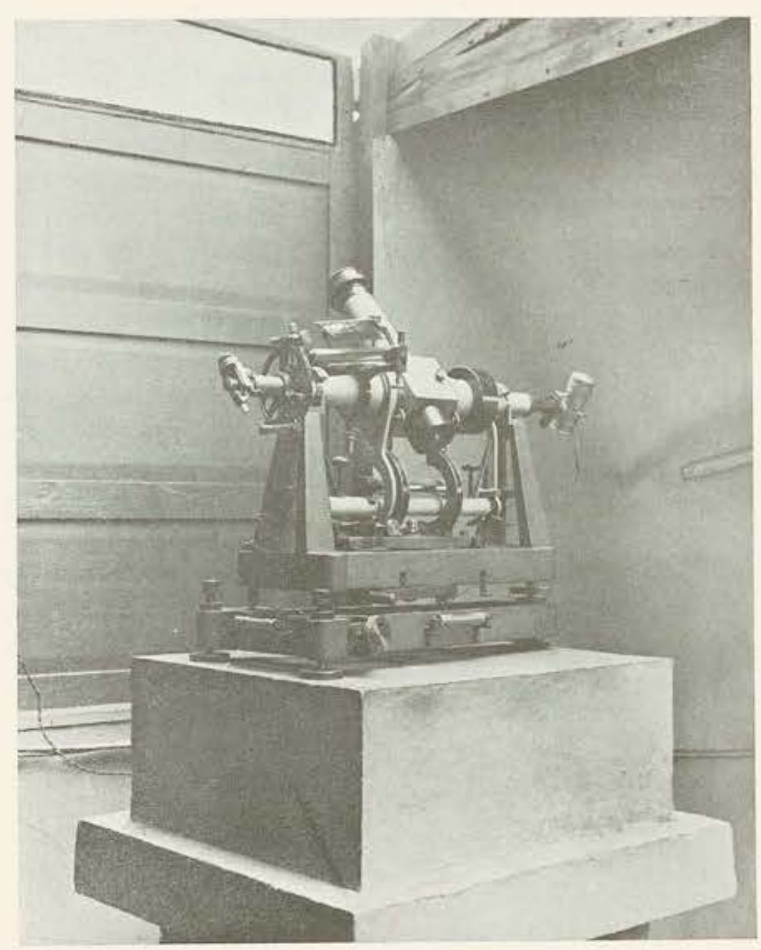

Anteojo de pasos Hayde (tipo Bamberg), con escala micrométrica especial para el método de Talcott. (Observatorio Astronómico)

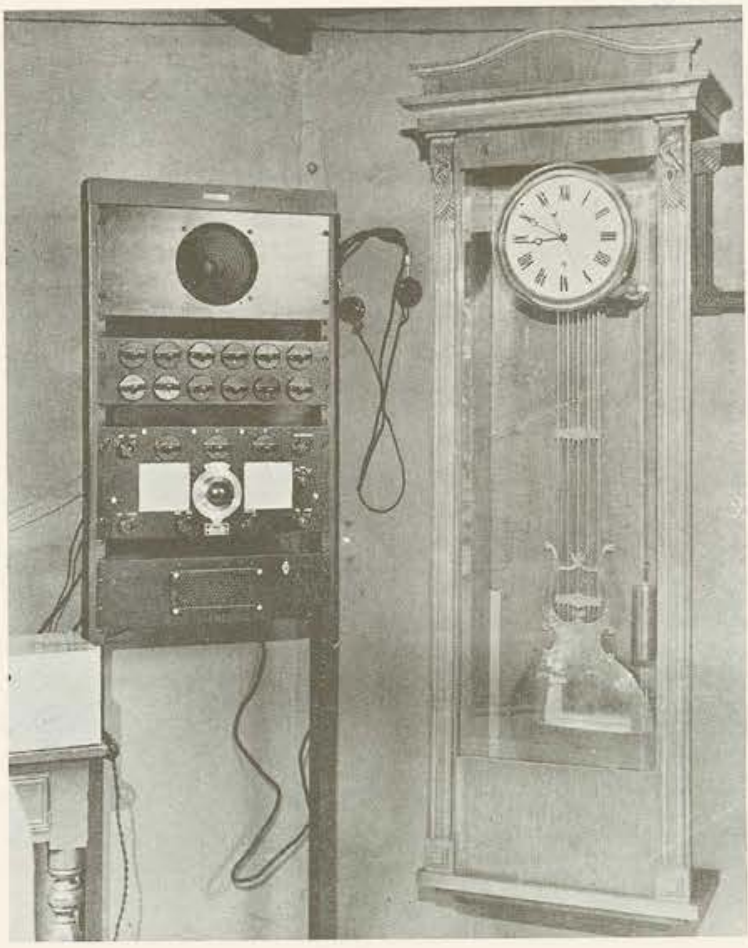

Pénduio sideral y aparato radiotelegráfico para el recibo de señales horarias. Casilla meridiana (Observatorio Astronómico) 
cilaciones del barómetro, to mismo que hallar la altura barométrica completamente corregida. También nos hemos propuesto facilitar, por cuantos medios se ha podido, a los ingenieros del país la confrontación y patronaje de sus barómetros, hipsómetros $\mathrm{y}$ aneroides.

En desarrollo de esta idea, durante mucho tiempo se han practicado las observaciones horarias del barómetro, primeramente cada dos horas y cada tres últimamente, para determinar de una manera absoluta las variaciones diurnas y las anuales. Estas observaciones se han hecho con un barómetro de "Fortin", de cubeta, con fondo movible, un tubo de $8 \mathrm{~mm}$. de diámetro y han dado los siguientes resultados, como valores medios, en cerca de veinte años.

Variaciones diurnas:

8 horas a. m., 0.561 .0 m.m.

9 horas a. m., $0.561 .2 \mathrm{~m} . \mathrm{m}$.

10 horas a. m., 0.561 .0 m.m.

12 horas $\mathrm{m}$. $0.560 .0 \mathrm{~m} . \mathrm{m}$.

Máxima nocturna, a las 10 p. m., 0.560 .8 m.m.;

2 horas u. m., 0.559 .3 m.m.

4 horas p. m. 0.558 .8 m.m.

6 horas p. m., 0.559 .3 m.m.

8 horas p. m., 0.560 .2 m.m.

Mínima nocturna, 3 horas $30^{\mathrm{m}}$ p. m., $0.559 .4 \mathrm{~m} . \mathrm{m}$.

La presión media, sacada de estos datos, resulta ser de $0{ }^{\mathrm{m}} 569.1, \mathrm{y}$ debe ser corregida del error índice del barómetro. La determinación de este error índice la hicimos por medio de un catetómetro "Perreaux", arreglado personalmente por nosotros, y que se empleó en determinar la distancia del enrace del mercurio a la división $550^{\mathrm{mm}}$ de la escala. Después de cierto número de lecturas, hechas con todas las precauciones usadas, sacamos como error medio de la escala $=0.35^{\mathrm{mm}}=0.05^{\mathrm{mm}}$ por exceso; de donde se deduce que la presión media verdadera es de $0 .{ }^{\mathrm{m}} 559.5$ o 0.559 .8 metros.

Esta altura asignada a la columna barométrica difiere de la que corresponde, en las tablas de Reg. nault, a la temperatura de ebullición del agua en Bogotá, según Liévano, en la cantidad de $1 .^{\mathrm{mm}} 126$.

La marcha seguida para la reducción de las ob. servaciones del barómetro ha sido la siguiente:

Si $B_{\text {o }}$ es la altura barométrica, reducida a cero, se pone: $B_{0}=B_{\mathrm{t}}-e+c-\gamma-\theta$. Fórmula en la cual $B_{\mathrm{t}}$ es la altura barométrica observada a $t^{\circ}, e$ es le error índice, determinado como se dijo, $c$ la corrección de capilaridad para un tubo de 8 milímetros de diámetro interno, $\theta$ la corrección de temperatura, por dilatación cúbica aparente del mercurio y dilatación lineal de la escala y $\gamma$ la corrección de la gravedad. Esta corrección ha sido calculada por la fórmula de Clarke.

Pongamos

$$
g=\frac{G}{1+0.002606 \cos 2 l} \cdot \frac{1}{1+\frac{2 h}{r}}
$$

en la cual $g$ es la intensidad de la gravedad a la latitud $l$ y a la altura $h$ sobre el nivel del mar, $G$ la intensidad de la gravedad al nivel del mar y a la latitud de $45^{\circ}$ y $r$ radio de la tierra correspondiente al lugar.

Si llamamos $B^{\prime}$ 。 la altura barométrica corregida de los tres primeros errores se pone:

$$
\frac{B_{\circ}}{B_{\circ}^{\prime}}=\frac{g}{G}=\frac{1}{1+0.002606 \cos 2 l} \cdot \frac{1}{1+\frac{2 h}{r}}
$$

y como

$$
\gamma=B_{\circ}^{\prime}-B_{\circ}=B_{\circ}^{\prime}\left[1-\frac{1}{1+0.002606 \cos 2 l}-\frac{1}{1+\frac{2 h}{r}}\right]
$$

se tendrá, para

$$
\begin{gathered}
l=4^{\circ} 35^{\prime} 55^{\prime \prime} 2 \quad \\
r=6378000 \text { metros: } \quad \gamma=0.0034 B^{\prime} .
\end{gathered}
$$

\begin{tabular}{|c|c|c|c|c|c|}
\hline & $\begin{array}{c}\text { Media } \\
\text { mensual }\end{array}$ & Oscilación & & $\begin{array}{c}\text { Media } \\
\text { mensual }\end{array}$ & Oseilación \\
\hline & & $\mathbf{m m}$. & & & $\mathrm{mm}$. \\
\hline Enero .............. & 0.55995 & 2.5 & Julio $\ldots \ldots \ldots \ldots \ldots$ & 0.56040 & 1.9 \\
\hline Febrero .............. & 0.56020 & 2.2 & Agosto $\ldots \ldots \ldots \ldots$ & 0.56025 & 2.7 \\
\hline Marzo $\ldots \ldots \ldots \ldots \ldots$ & 0.55980 & 2.3 & Septiembre $\ldots \ldots \ldots \ldots$ & 0.56020 & 2.7 \\
\hline Abril $\ldots \ldots \ldots \ldots \ldots \ldots$ & 0.55995 & 2.6 & Octubre $\ldots \ldots \ldots \ldots \ldots$ & 0.55980 & 2.7 \\
\hline Mayo ............... & 0.56010 & 2.5 & Noviembre $\ldots \ldots \ldots \ldots$ & 0.55945 & 2.6 \\
\hline Junio $\ldots \ldots \ldots \ldots \ldots \ldots$ & 0.56035 & 2.1 & Diciembre...$\ldots \ldots \ldots$ & 0.55950 & 2.5 \\
\hline
\end{tabular}

Las oscilaciones anuales, dadas mes por mes, del barómetro corregido, son:
Este cuadro y el gráfico de las variaciones diurnas muestran cuál es la amplitud máxima de la oscilación. Según esto, los valores anotados por el doctor Carrasquilla son demasiado grandes.

$$
\text { *** }
$$

Concluyamos esta parte estudiando brevemente el aparato para corrección de barómetros aneroides, cuyo dibujo se acompaña. Compónese en sus partes esenciales, de una caja de palastro de doble fondo $G$ provista de un aro, al cual se sujeta, en tre arandelas de goma elástica, y por medio de fuertes tornillos de presión, un vidrio grueso. En el interior de la caja se colocan los instrumentos que se van a patronar, sobre un soporte de pies de corcho, en el cual se coloca también un termómetro. El tubo $T^{\prime}$ de acceso a la caja, viene de un depósito de palastro $D$ donde se comprime el aire por medio de una bomba de mano $B$. El depósito está provisto de un manómetro de resorte $\mathrm{y}$ de dos llaves, para 
cerrar o abrir las comunicaciones con la caja o con la bomba de compresión. El tubo $T^{\prime \prime}$ provisto de su llave respectiva, termina en un manómetro de mercurio $M$.

Para elevar gradualmente la temperatura, entre el doble fondo de la caja $C$ se calienta agua lentamente por medio del hornillo $H$ agua que se puede enfriar por medio de hielo machacado.

La lectura de la columna de mercurio se hace con el catetómetro. Este aparato, así descrito sirve para hacer marcar al aneroide que se ensaya, presiones crecientes desde $560 \mathrm{~mm}$. hasta $800 \mathrm{~mm}$. de mercurio. De centímetro en centímetro, se leen el aneroide y la altura de la columna en el manómetro. Después se lee el barómetro de Fortin, y a la altura barométrica se agrega la manométrica. La suma representa la altura de la columna para la presión indicada, una vez hechas las correcciones de capilaridad, temperatura y gravedad.

La diferencia entre este resultado y la lectura del aneroide, a la temperatura marcada por el termómetro interior, da el error del aparato a esa presión.

\section{CONCLUSION}

Una lectura atenta de la presente Memoria, en donde he procurado historiar de la mejor manera el desarrollo de los estudios meteorológicos en Co. lombia, y donde he puesto de manifiesto el estado actual de este Servicio oficial en la República, llevará al espíritu la idea de que en este terreno se presenta un campo de investigación inexplorado aún. Relativamente mucho se ha hecho en este sentido, mas queda todavía gran parte por hacer, tratando de extender los estudios climatológicos a todas las regiones del país que hasta ahora son casi desconocidas para la Meteorología.

El fin práctico de este trabajo es, en consecuencia, indicar la necesidad de ampliar el radio de las observaciones organizando un Servicio Meteorológico Nacional que continúe la obra del Observato. rio de Bogotá, siguiendo las indicaciones que en el día son fruto de una experimentación relativamente larga $\mathbf{y}$ cuidadosa.

Natural parece, pues, terminar el estudio que presento con el siguiente proyecto de ley, que puede someterse a la aprobación del próximo Congreso:

"10-Por el Ministerio de Instrucción Pública se procederá a la organización del Servicio Meteorológico del pais, tan pronto como esta ley sea promulgada. Tal organización se hará en detalle, consultando las necesidades de la Nación y la marcha de servicios similares en otras repúblicas americanas.

" $2^{\circ}$-El Director del Observatorio Astronómico Nacional será el Jefe de este Servicio; y en cuanto a plan científico de observaciones, se seguirán desarrollando los métodos empleados hasta ahora por el Observatorio, con las modificaciones que consulten mejor las necesidades de la Estadística agríco. la y de la fluviometría del territorio.
"3ํ-Por el Ministerio de Instrucción Pública se darán los pasos conducentes a obtener la colaboración eficaz, en esta obra, de los Observatorios Me. teorológicos de la Universidad de Antioquia, de los RR. PP. Agustinos de Barranquilla y de la Universidad del Cauca.

" $4^{\circ}$ - Por el mismo Ministerio se encargará, mediante un sobresueldo mensual, a los señores profesores de Física de los establecimientos enumerados a continuación, la colección de datos diurnos relativos a cantidad de lluvia caída, dirección predominante en intensidad de las corrientes atmosféricas y cambios de temperatura. Estos profesores serán de la Universidad de Cartagena, del Colegio de Boyacá, de la Universidad del Cauca, de las Escuelas Normales de Manizales, Neiva, Santa Marta, Cúcuta, Pamplona, San Gil, Cali y Montería, del Colegio de "San Simón" de Ibagué, del Colegio de "Jesús María y José" de Chiquinquirá, del Colegio de "San Pedro Claver" de Bucaramanga, de la Universidad de Nariño, del Instituto Pedagógico de Tumaco y de las Escuelas Públicas de Quibdó.

" $5^{\circ}$-Por el Ministerio de Obras Públicas se obtendrán datos semejantes y en las mismas condiciones, del F. C. del Pacífico, en Buenaventura; del F. C. de Cúcuta, en Puerto Villamizar; del F. C. de Antioquia, en Puerto Berrío y Cisneros; del F. C. de Puerto César, en Puerto César y Turbo; del F. C. de Puerto Wilches, en Puerto Wilches y Puerto Santos; del F. C. de Girardot, en Girardot y La Esperanza; del F. C. de La Dorada, en Honda y La Dorada.

" 6 —-Se establecerán Oficinas Meteorológicas especiales, que tomen diariamente los mismos datos, en Calamar del Vaupés, Mocoa, Arauca y Riohacha.

"7-Los empleados del Servicio Meteorológico en Riohacha, Calamar del Vaupés, Mocoa y Arauca, dependerán de los Jefes Políticos de cada lugar y devengarán del Tesoro Nacional un sueldo equitativo.

" 8 -Los pluviómetros y termómetros usados por los encarga dos de colectar los datos meteorológicos, serán suministrados por el Observatorio Nacional bajo un patrón rigurosamente uniforme.

" 9 - Cada ocho días se remitirán a la Oficina Meteorológica Central los datos recogidos, sin perjuicios de comunicar telegráficamente aquellos fenómenos (tempestades, súbitos cambios de temperatura, granizadas, etc.) que requieran un registro especial.

"10.-En Bogotá, Medellín, Barranquilla y Popayán, donde existan Observatorios meteorológicos ya organizados, se registrarán las variaciones del barómetro a horas determinadas.

"11.- Todos los datos recogidos en el país serán dispuestos dos veces al mes, por la Oficina Central del Observatorio, en cartas y gráficos convenientes, según las últimas Convenciones Meteorológicas. Estas cartas, gráficos, cuadros respectivos, etc., junto con las observaciones practicadas en Bogotá sobre el actinómetro, la superficie solar y el potencial eléctrico, verán la luz pública en un "Boletín Men. 
sual del Observatorio Nacional", editado en la Im. prenta Nacional y que se enviará a todas las capi. tales de los Departamentos, a los Institutos de Agricultura, a las Empresas de Navegación, a las Compañias de Seguros Agrícolas, etc., y se canjeará con todas las publicaciones similares del Ex. terior.

"12.-El Director del Observatorio Nacional tendrá bajo su inmediata dependencia un ingeniero graduado encargado de la ordenación de datos, dibujo de los gráficos respectivos, organización de las observaciones, patronamiento de los aparatos, publicación del Boletín, etc., etc.

"13.-Los nombramientos en el ramo del Servicio Meteorológico se harán por el Ministerio de Instrucción Pública, de ternas presentadas por el señor Director del Observatorio.

"14.-Los empleados del Servicio Meteorológico y los Institutos que remitan datos al Observatorio gozarán de franquicia telegráfica y postal.

"15.-Los gastos que ocasione el cumplimiento de la presente ley serán de cargo del Tesoro Nacional y quedan incluídos en el presupuesto en vigencia, etc.".

Las siguientes razones motivan la presentación de este proyecto de ley que, como se dijo, es de importancia notoria para el progreso industrial y agrícola del país:

$1^{\text {a }}$ En el artículo $1^{\circ}$ del proyecto se enuncia claramente. Esta razón es de peso, si se considera que no debe tardar el día en que se convoque a una Conferencia Internacional Meteorológica, en alguna de las repúblicas hispanas. Vergonzoso sería para Colombia aparecer con las manos vacías en un certamen de trascendencia, cuando todos los países han organizado u organizan en la actualidad su Servicio Meteorológico, y cuando, precisamente, en el privilegiado territorio de Colombia, tuvo origen la ciencia meteorológica, con las observaciones de Humboldt, Boussingault, Bourdon, Gaudot, Roulin y otros (entre ellos Caldas).

$2^{a}$ Los datos meteorológicos que se han tomado en Bogotá, desde el tiempo de Caldas, y en Medellín, Barranquilla y Popayán, en épocas recientes, son elementos aislados que a lo sumo hacen conocer el clima de cada localidad, con las leyes a que obedecen sus variaciones, pero que nunca permitirán verificar el conocimiento del clima general del país, ni mucho menos prestar servicio efectivo a la agricultura nacional.

$3^{2}$ Las estadísticas agrícolas, que hoy sirven en todo el mundo para las Compañías de Seguros, pres. tando a la agricultura inmensos servicios con un ramo especial de aseguro, tienen su fundamento en las estadísticas meteorológicas y en el conocimiento de los elimas regionales.

$4^{\text {a }}$ En muchas circunstancias, las empresas de acueductos urbanos, las compañías de navegación fluvial; las empresas de canalización; las sociedades de agricultura, etc., necesitan indispensablemente de las estadísticas meteorológicas. Esta necesidad se hará sentir de una manera imperiosa cuando se organice un servicio de irrigacion eficaz, se extiendan los cultivos de secano y la agricultura nacional, abandonando procedimientos rutinarios, deje de ser un juego de suerte y azar.

$5^{q}$ El establecimiento del Servicio Meteorológico en Colombia será útil a la Meteorología universal, pues contribuirá al mejor conocimiento de las leyes que rigen los fenómenos meteorológicos en las regiones equinocciales. 